\title{
CONVECTIVE FLOW OF HYDROMAGNETIC COUPLE STRESS FLUID WITH VARYING HEATING THROUGH VERTICAL CHANNEL
}

\author{
C.R. MAKHALEMELE and L. RUNDORA* \\ Department of Mathematics and Applied Mathematics, University of Limpopo \\ Private Bag X1106, Sovenga 0727, SOUTH AFRICA \\ E-mail: lazarus.rundora@ul.ac.za \\ S.O. ADESANYA \\ Department of Mathematical Sciences, Redeemer's University \\ Ede, NIGERIA
}

\begin{abstract}
This article addresses the impact of magnetic field induction on the buoyancy-induced oscillatory flow of couple stress fluid with varying heating. Modelled equations for the incompressible fluid are coupled and nonlinear due to the inclusion of viscous heating and thermal effect on the fluid density. Approximate solutions are constructed and coded on a symbolic package to ease the computational complexity. Graphical representations of the symbolic solutions are presented with detailed explanations. Results of the present computation show that the effect of induced magnetic field on the oscillatory flow and heat transfer is significant and cannot be neglected.
\end{abstract}

Key words: induced magnetic field, couple stresses, vertical channel, varying heating.

\section{Introduction}

The convective flow of a viscous fluid subjected to periodic heating and cooling plays a vital role in a huge number of home appliances, industry, geology and geophysics, medicine, aerodynamics and much more. In a study by Wang [1], the equations for the buoyancy-induced flow were modelled and separated into steadyperiodic regimes. Jha and Ajibade [2-4] popularized the approach by conducting studies under different flow conditions. Following the analysis is a study by Adesanya [5] on a micro-channel flow with partial slip and thermal conditions. More recently, Adesanya et al. [6] presented results for magnetohydrodynamic convective flows in steady-periodic regimes with constant magnetic fields. Several other related studies on convective flow problems with or without a magnetic field can be seen in papers [6-11] and lots more in the literature.

In many cases of engineering interest, induced magnetic fields usually act as a flow control mechanism, especially under intense heat. The following studies were conducted by taking an induced magnetic field into consideration, Ahmed [12] studied the double diffusivity in a developing flow. Raju et al. [13] focused on the convective flow over a stretching surface. Iqbal et al. [14] presented a numerical study on a developing nanofluid stagnation point flow. In similar work, Animasaun and his associates [15], examined the radiative viscoelastic stagnation point flow. Sheikholeslami et al. [16] presented an analysis of a convective nanofluid problem using Koo-Kleinstrever-Li correlation method. Noreem et al. [17] investigated a pseudo-plastic peristaltic fluid flow. Kumar and Singh [18] addressed the radial flow through a vertical cylinder with constant heat source. Gosh et al. [19] constructed a solution for a convective fluid flow. Raju et al. [20] analyzed the stagnation point flow. A numerical study of natural convection was discussed extensively by Kumar and Singh [21]. In fact, there are several investigations in various fluid flow problems relating to electrically conducting fluid with induced magnetic fields, some of these can be found in papers [22-34] and references therein.

\footnotetext{
${ }^{*}$ To whom correspondence should be addressed
} 
One major characteristic that distinguishes the couple stress fluid among other non-Newtonian fluids is the inclusion of size-dependent microstructure that is of mechanical significance. As explained by Stokes [35] in the couple stress theory, the couple stress constitutive model can easily give an explanation for couple stresses, the effect of body couples and the non-symmetric stress tensor manifested in several real fluids of technological importance. This important class of fluids has been used extensively in the literature to explain the non-Newtonian behaviour of some real fluid. In view of the huge available references, few of these studies on couple stresses will be described here. Srinivasacharya and Kaladhar [36] applied the model to study the convective flow behaviour in reacting fluids. Srinivas et al. [37] applied the model for flow with varying properties. In the study by Srinivas et al. [38], the micropolar fluid flow in a non-Darcian medium was reported. A similar work by Mahabaleshwar et al. [39] addressed the hydromagnetic case over a leaky stretching sheet. Kaladar et al. [40] examined the diffusivity problem in a vertical configuration. Ali et al. [41] analyzed the MHD oscillatory flow over a stretching surface. Kan et al. [42] derived an exact solution of hydromagnetic couple stress fluid using the wave transformation approach. Hayat et al. [43] examined the developing case in a moving surface subjected to internal heat generation and Newtonian heating. Srinivas and Murthy [44] studied the entropy build-up in immiscible couple stress fluids in a channel flow. Adesanya et al. [45] reported the effect of couple stresses on the hydromagnetic viscoelastic fluid flow. Eldabe and his collaborators [46] discussed the pulsatile flow between solid boundaries. Other interesting results on the application of the couple stress theory is not limited to [47-51] and the cited references.

The above studies on the induced magnetic field motivates the present study on the convective couple stress fluid undergoing steady-periodic heating, which has not been done despite the huge number of studies reported on the size-dependent effect. In the following section, the Mathematical analysis for the problem will be presented and the dimensionless coupled boundary-valued-problem would be solved by the Adomian decomposition method. Interested readers can see the detailed review, theory and huge applications of the method in [52-56]. Section 3 of the paper deals with presentation and discussion of results while the paper is concluded in section 4 .

\section{Mathematical analysis}

Consider a 2-dimensional unsteady couple stress fluid flow with a velocity vector $\bar{q}=(u, v, 0)$ together with the magnetic induction vector $\bar{H}=\left(b_{x}, b_{y}, 0\right)$.

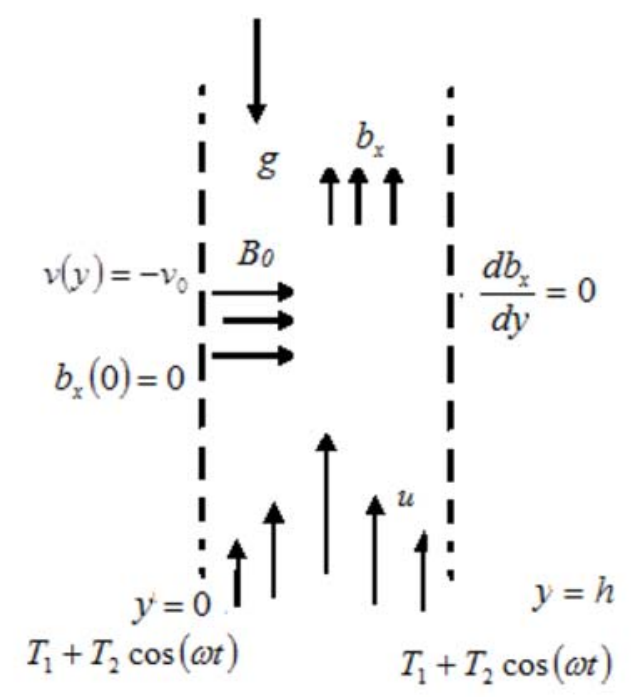

Fig.1. Physical model of the problem. 
The channel half-width is taken to be $h$ and normal to the channel length while the $\mathrm{x}$-axis is normal to the channel length as shown in Fig.1. The channel length is assumed to be long enough for the flow to be fully developed. In formulating the model, only variations of fluid density and heat source/sink with temperature are considered. The present formulation also catered for dissipations due to fluid friction, couple stresses, and electric charges. With large magnetic suction, the induced magnetic field is also considered. Thus, in vector form we have $[6,16]$ :

conservation of electric charge:

$$
\frac{\partial \rho}{\partial t}+\nabla \cdot J=0
$$

conservation of mass:

$$
\frac{\partial \rho}{\partial t}+\nabla \cdot(\rho \bar{q})=0
$$

Gauss' law of magnetism:

$$
\nabla \cdot \bar{H}=0
$$

momentum equation:

$$
\rho\left(\frac{\partial \bar{q}}{\partial t}+(\bar{q} \cdot \nabla) \bar{q}\right)=-\nabla P+\mu \nabla^{2} \bar{q}+\mu_{e}(\bar{J} \times \bar{H})-\tau \nabla^{2}\left(\nabla^{2} \bar{q}\right)+\rho \bar{g},
$$

energy equation:

$$
\rho C_{p}\left(\frac{\partial T}{\partial t}+(\bar{q} \cdot \nabla) T\right)=k \nabla^{2} T+\mu(\nabla \bar{q})^{2}+\frac{1}{\sigma}(\nabla \bar{H})^{2}+\tau\left(\nabla^{2} \bar{q}\right)^{2}+Q_{0}\left(T_{0}-T\right),
$$

conservation of magnetic induction:

$$
\frac{\partial \bar{H}}{\partial t}+\nabla \times(\bar{q} \times \bar{H})=\frac{1}{\sigma \mu_{e}} \nabla^{2} \bar{H} .
$$

Neglecting the variation of fluid density with time and from Eq.(2.2), the fully developed case implies that $v(y)=-v_{0}$, i.e. a constant. In the first approximation, by assuming a small velocity gradient in the momentum equation and eliminating the pressure gradient, we get

$$
\begin{aligned}
& \frac{\partial u}{\partial t}-v_{0} \frac{\partial u}{\partial y}=v \frac{\partial^{2} u}{\partial y^{2}}+\frac{\mu_{e} b_{0}}{\rho} \frac{\partial b_{x}}{\partial y}+g \beta\left(T-T_{0}\right)-\frac{\tau}{\rho} \frac{\partial^{4} u}{\partial y^{4}}, \\
& \frac{\partial b_{x}}{\partial t}-v_{0} \frac{\partial b_{x}}{\partial y}=b_{0} \frac{\partial u}{\partial y}+\frac{1}{\mu_{e} \sigma} \frac{\partial^{2} b_{x}}{\partial y^{2}},
\end{aligned}
$$


with

$$
\rho c_{p}\left(\frac{\partial T}{\partial t}-v_{0} \frac{\partial T}{\partial y}\right)=k \frac{\partial^{2} T}{\partial y^{2}}+\mu\left(\frac{\partial u}{\partial y}\right)^{2}+\frac{1}{\sigma}\left(\frac{\partial b_{x}}{\partial y}\right)^{2}+\tau\left(\frac{\partial^{2} u}{\partial y^{2}}\right)^{2}+Q_{0}\left(T_{0}-T\right)
$$

$$
\begin{aligned}
& u^{\prime}(0)=u^{\prime \prime}(0)=0, \quad b_{x}(0)=0, \quad T(0)=T_{1}+T_{2} \cos (\omega t), \quad y=0, \\
& u(h)=u^{\prime \prime}(h)=0, \quad b_{x}(l)=0, \quad T(h)=T_{1}+T_{2} \cos (\omega t), \quad y=h .
\end{aligned}
$$

We introduce the following

$$
\left\{\begin{array}{l}
u(t, y)=\frac{g \beta h^{2}}{v}\left[\left(T_{1}-T_{0}\right) A(y)+T_{2} B(y) e^{i \omega t}\right], \\
T(t, y)=T_{0}+\left(T_{1}-T_{0}\right) F(y)+T_{2} G(y) e^{i \omega t}, \\
b_{x}(t, y)=\frac{g \beta h^{2}}{v}\left(\frac{\mu_{e}}{\rho}\right)^{-\frac{1}{2}}\left[\left(T_{1}-T_{0}\right) L(y)+T_{2} M(y) e^{i \omega t}\right],
\end{array}\right.
$$

along with the dimensionless quantities

$$
\left\{\begin{array}{l}
\eta=\frac{Y}{h}, \quad \lambda=\frac{\mu}{k}\left(\frac{g \beta h^{2}}{v}\right)^{2}\left(T_{1}-T_{0}\right), \quad \text { St }=\frac{h^{2} \omega}{v}, \quad \operatorname{Pr}=\frac{\mu C_{p}}{k}, \\
H=\frac{b_{0} h}{v} \sqrt{\frac{\mu_{e}}{\rho}}, \quad \kappa^{2}=\frac{h^{2} \mu}{\tau}, \quad \delta=\frac{Q_{0} h^{2}}{k}, \quad P_{m}=\sigma v \mu_{e}, \quad s=\frac{v_{0} h}{v},
\end{array}\right.
$$

giving rise to the following orders of perturbations:

$$
\left\{\begin{array}{l}
o\left(e^{i \omega t}\right)^{0}: A^{(4)}(\eta)=\kappa^{2}\left(A^{\prime \prime}(\eta)+s A^{\prime}(\eta)+H L^{\prime}(\eta)+F(\eta)\right), \\
\mathrm{A}(0)=0=A^{\prime \prime}(0)=\mathrm{A}(1)=A^{\prime \prime}(1), \\
L^{\prime \prime}(\eta)=-\left(s P_{m} L^{\prime}(\eta)+H P_{m} A^{\prime}(\eta)\right) ; \quad L(0)=0=L(1), \\
F^{\prime \prime}(\eta)=\delta F(\eta)-s \operatorname{Pr} F^{\prime}(\eta)-\lambda\left(A^{\prime}(\eta)^{2}+\frac{A^{\prime \prime}(\eta)^{2}}{\kappa^{2}}+\frac{L^{\prime}(\eta)^{2}}{P_{m}}\right), \\
F(0)=1=F(1),
\end{array}\right.
$$




$$
\left\{\begin{array}{l}
o\left(e^{i \omega t}\right)^{l}: B^{(4)}(\eta)=\kappa^{2}\left(B^{\prime \prime}(\eta)+s B^{\prime}(\eta)-i S t B(\eta)+H M^{\prime}(\eta)+G(\eta)\right), \\
\mathrm{B}(0)=0=B^{\prime \prime}(0)=B(l)=B^{\prime \prime}(1), \\
M^{\prime \prime}(\eta)=P_{m}\left(i S t B(\eta)-s M^{\prime}(\eta)+H B^{\prime}(\eta)\right), \quad M(0)=0=M(1), \\
G^{\prime \prime}(\eta)=(\delta+i S t \operatorname{Pr}) F(\eta)-s \operatorname{Pr} G^{\prime}(\eta)-2 \lambda A^{\prime}(\eta) B^{\prime}(\eta)-\frac{2 \lambda}{\kappa^{2}} A^{\prime \prime}(\eta) B^{\prime \prime}(\eta), \\
-\frac{2 \lambda}{P_{m}} L^{\prime}(\eta) M^{\prime}(\eta), \quad G(0)=1=G(1) .
\end{array}\right.
$$

\section{Adomian decomposition method of solution}

As shown in [56], the Adomian decomposition method (ADM) is a well-established method for solving differential equations. In what follows, the coupled differential equations in Eqs (2.13)-(2.14) with the boundary conditions give the equivalent integral equations that are given by:

$$
\begin{aligned}
& A(\eta)=\int_{0}^{\eta} \frac{d A(0)}{d Y} d Y+\int_{0}^{\eta} \int_{0}^{\eta} \int_{0}^{\eta}\left(\frac{d^{3} A(0)}{d Y^{3}}\right) d Y d Y d Y+ \\
& +\int_{0}^{\eta} \int_{0}^{\eta} \int_{0}^{\eta} \int_{0}^{\eta} \kappa^{2}\left(A^{\prime \prime}(Y)+s A^{\prime}(Y)+H L^{\prime}(Y)+F(Y)\right) d Y d Y d Y d Y, \\
& B(\eta)=\int_{0}^{\eta} \frac{d B(0)}{d Y} d Y+\int_{0}^{\eta} \int_{0}^{\eta} \int_{0}^{\eta}\left(\frac{d^{3} B(0)}{d Y^{3}}\right) d Y d Y d Y+ \\
& +\int_{0}^{\eta} \int_{0}^{\eta} \int_{0}^{\eta} \int_{0}^{\eta} \kappa^{2}\left(B^{\prime \prime}(Y)+s B^{\prime}(Y)+H M^{\prime}(G)-i S t B(Y)+G(Y)\right) d Y d Y d Y d Y, \\
& F(\eta)=1+\int_{0}^{\eta} \frac{d F(0)}{d Y} d Y+\int_{0}^{\eta} \int_{0}^{\eta}\left(\delta F(Y)-s \operatorname{Pr} F^{\prime}(Y)\right) d Y d Y+ \\
& -\lambda \int_{0}^{\eta} \int_{0}^{\eta}\left(A^{\prime}(Y)^{2}+\frac{A^{\prime \prime}(Y)^{2}}{\kappa^{2}}+\frac{L^{\prime}(Y)^{2}}{P_{m}}\right) d Y d Y,
\end{aligned}
$$




$$
\begin{aligned}
& G(\eta)=1+\int_{0}^{\eta} \frac{d G(0)}{d Y} d Y+\int_{0}^{\eta} \int_{0}^{\eta}(\delta+i S t \operatorname{Pr}) F(Y)-s \operatorname{Pr} G^{\prime}(Y) d Y d Y+ \\
& -2 \lambda \int_{0}^{\eta} \int_{0}^{\eta}\left(A^{\prime}(Y) B^{\prime}(Y)+\frac{A^{\prime \prime}(Y) B^{\prime \prime}(Y)}{\kappa^{2}}+\frac{L^{\prime}(Y) M^{\prime}(Y)}{P_{m}}\right) d Y d Y, \\
& L(\eta)=\int_{0}^{y} \frac{d L(0)}{d Y} d Y-\int_{0}^{\eta} \int_{0}^{\eta}\left(s P_{m} L^{\prime}(Y)+H P_{m} A^{\prime}(Y)\right) d Y d Y, \\
& M(\eta)=\int_{0}^{\eta} \frac{d M(0)}{d Y} d Y+\int_{0}^{\eta} \int_{0}^{\eta} P_{m}\left(i S t B(\eta)-s M^{\prime}(\eta)+H B^{\prime}(\eta)\right) d Y d Y .
\end{aligned}
$$

The standard assumed series is of the form:

$$
\left\{\begin{array}{lll}
A(\eta)=\sum_{n=0}^{\infty} A_{n}(\eta), & B(\eta)=\sum_{n=0}^{\infty} B_{n}(\eta), & F(\eta)=\sum_{n=0}^{\infty} F_{n}(\eta), \\
G(\eta)=\sum_{n=0}^{\infty} G_{n}(\eta), & L(\eta)=\sum_{n=0}^{\infty} L_{n}(\eta), & M(\eta)=\sum_{n=0}^{\infty} M_{n}(\eta) .
\end{array}\right.
$$

Substituting Eqs (3.7) in Eqs (3.1)-(3.6), we get

$$
\left.A_{0}(\eta)=\int_{0}^{\eta} a_{1} d Y+\int_{0}^{\eta} \int_{0}^{\eta} \int_{0}^{\eta} a_{2} d Y d Y d Y ; L_{0}(\eta)=\int_{0}^{y} l_{0} d Y ; F_{0}(\eta)=1+\int_{0}^{y} f_{0} d Y\right\}
$$

with the recurrence relations:

$$
\left\{\begin{array}{l}
A_{n+1}(\eta)=\int_{0}^{\eta} \int_{0}^{\eta} \int_{0}^{\eta} \int_{0}^{\eta} \kappa^{2}\left(A_{n}{ }^{\prime \prime}(Y)+s A_{n}{ }^{\prime}(Y)+H L_{n}{ }^{\prime}(Y)+F_{n}(Y)\right) d Y d Y d Y d Y \\
L_{n+1}(\eta)=-\int_{0}^{\eta} \int_{0}^{\eta}\left(s P_{m} L_{n}{ }^{\prime}(Y)+H a P_{m} A_{n}{ }^{\prime}(Y)\right) d Y d Y \\
F_{n+1}(\eta)=\int_{0}^{\eta} \int_{0}^{\eta}\left(\delta F_{n}(Y)-s \operatorname{Pr} F_{n}{ }^{\prime}(Y)-\lambda K_{n}\right) d Y d Y
\end{array}\right.
$$

Similarly, in the periodic flow regime 


$$
B_{0}(\eta)=\int_{0}^{\eta} b_{1} d Y+\int_{0}^{\eta} \int_{0}^{\eta} \int_{0}^{\eta} b_{2} d Y d Y d Y, \quad M_{0}(\eta)=\int_{0}^{y} m_{0} d Y, \quad G_{0}(\eta)=1+\int_{0}^{y} g_{0} d Y
$$

while the rest of the terms are given by

$$
\left\{\begin{array}{l}
B_{n+1}(\eta)=\int_{0}^{\eta} \int_{0}^{\eta} \int_{0}^{\eta} \int_{0}^{\eta} \kappa^{2}\left(B_{n}{ }^{\prime \prime}(Y)+s B_{n}{ }^{\prime}(Y)+H M_{n}{ }^{\prime}(G)-i S t B_{n}(Y)+G_{n}(Y)\right) d Y d Y d Y d Y \\
G_{n+1}(\eta)=\int_{0}^{\eta} \int_{0}^{\eta}\left((\delta+i S t \operatorname{Pr}) F_{n}(Y)-s \operatorname{Pr} G_{n}{ }^{\prime}(Y)-2 \lambda U_{n}\right) d Y d Y, \\
M_{n+1}(\eta)=\int_{0}^{\eta} \int_{0}^{\eta} P_{m}\left(i S t B_{n}(\eta)-s M_{n}^{\prime}(\eta)+H B_{n}^{\prime}(\eta)\right) d Y d Y
\end{array}\right.
$$

where

$$
\left\{\begin{array}{l}
K_{n}=\left(\frac{d A_{n}}{d Y}\right)^{2}+\frac{1}{\kappa^{2}}\left(\frac{d^{2} A_{n}}{d Y^{2}}\right)^{2}+\frac{1}{p_{m}}\left(\frac{d L_{n}}{d Y}\right)^{2}, \\
U_{n}=\left(\frac{d A_{n}}{d Y}\right)\left(\frac{d B_{n}}{d Y}\right)+\frac{1}{\kappa^{2}}\left(\frac{d^{2} A_{n}}{d Y^{2}}\right)\left(\frac{d^{2} B_{n}}{d Y^{2}}\right)+\frac{1}{p_{m}}\left(\frac{d L_{n}}{d Y}\right)\left(\frac{d M_{n}}{d Y}\right),
\end{array}\right.
$$

the appropriate Adomian Polynomials are:

$$
\left\{\begin{array}{l}
K_{0}=\left(\frac{d A_{0}}{d Y}\right)^{2}+\frac{1}{\kappa^{2}}\left(\frac{d^{2} A_{0}}{d Y^{2}}\right)^{2}+\frac{1}{p_{m}}\left(\frac{d L_{0}}{d Y}\right)^{2}, \\
K_{l}=2\left(\frac{d A_{0}}{d Y}\right)\left(\frac{d A_{1}}{d Y}\right)+\frac{2}{\kappa^{2}}\left(\frac{d^{2} A_{0}}{d Y^{2}}\right)\left(\frac{d^{2} A_{1}}{d Y^{2}}\right)+\frac{2}{p_{m}}\left(\frac{d L_{0}}{d Y}\right)\left(\frac{d L_{1}}{d Y}\right), \\
\ldots \ldots . \\
U_{0}=\left(\frac{d A_{0}}{d Y}\right)\left(\frac{d B_{0}}{d Y}\right)+\frac{1}{\kappa^{2}}\left(\frac{d^{2} A_{0}}{d Y^{2}}\right)\left(\frac{d^{2} B_{0}}{d Y^{2}}\right)+\frac{1}{p_{m}}\left(\frac{d L_{0}}{d Y}\right)\left(\frac{d M_{0}}{d Y}\right), \\
\left.+\left(\frac{d^{2} A_{0}}{d Y^{2}}\right)\left(\frac{d^{2} B_{1}}{d Y^{2}}\right)\right)+\frac{2}{p_{m}}\left(\left(\frac{d L_{0}}{d Y}\right)\left(\frac{d B_{1}}{d Y}\right)+\left(\frac{d A_{1}}{d Y}\right)\left(\frac{d B_{0}}{d Y}\right)\right)+\frac{2}{\kappa^{2}}\left(\left(\frac{d^{2} A_{1}}{d Y^{2}}\right)\left(\frac{d^{2} B_{0}}{d Y^{2}}\right)+\right. \\
\left.U_{1}\right)
\end{array}\right.
$$


The iterative processes (3.8)-(3.13) are then coded into MATHEMATICA version 10.0 for easy iteration. Expressions for the unknown constants are also obtained with the aid of the remaining boundary conditions. At the end we obtain the following $\mathrm{q}^{\text {th }}$ partial sums as the approximate solutions of the coupled differential equations.

$$
\begin{aligned}
& A(\eta)=\sum_{n=0}^{q} A_{n}(\eta), \quad B(\eta)=\sum_{n=0}^{q} B_{n}(\eta), F(\eta)=\sum_{n=0}^{q} F_{n}(\eta), \\
& G(\eta)=\sum_{n=0}^{q} G_{n}(\eta), L(\eta)=\sum_{n=0}^{q} L_{n}(\eta), \quad M(\eta)=\sum_{n=0}^{q} M_{n}(\eta) .
\end{aligned}
$$

Finally, the induced current density is given by

$$
J=-\frac{d L}{d y}, \quad K=-\frac{d M}{d y}
$$

in the steady and periodic flow regimes, respectively.

\section{Results and discussion}

Equations (3.8)-(3.14) are carefully coded in MATHEMATICA version 10.0 for easy iteration of the Adomian decomposition procedure. The following symbolic solutions are obtained graphically due to a large output of the computation. Figure 2 represents the variation of some important fluid parameters in the steady flow. As shown in Fig.2a, an increase in the magnetic field parameter is seen to decrease the flow velocity because ferrofluid particles agglomerate with increasing induced magnetic field, also the retarding effect of Lorentz forces. The variation of the couple stress inverse parameter in the steady flow velocity is also shown in Fig.2b. From the graphical result, an increase in the couple stress inverse parameter is seen to enhance the flow velocity. In other words, an increase in the couple stress inverse parameter means a decrease in the nonNewtonian behaviour of the fluid. Hence, an increase in the couple stress parameter is seen to decrease the flow velocity. In Fig.2c, an increase in the viscous heating parameter is observed to enhance the fluid velocity due to increased heat generated in the fluid. Moreover, as presented in Fig.2d, an increase in the magnetic Prandtl number is observed to decrease the steady flow significantly due to increased induced magnetic field. Similarly, Fig.2e shows that an increase in the suction Reynolds's number is seen to decrease the flow velocity as much fluid is sucked away from the flow domain. A closer view of Fig.2g revealed the effect of Prandtl number on the fluid flow; it is also observed that the flow velocity decreases with increased Prandtl number since the fluid dynamic viscosity increases. Finally, Fig.2f shows that as the heat sink parameter increases, the fluid velocity distribution within the flow declines accordingly due to heat loss to the ambient.

Figure 3 depicts the variation of steady temperature with pertinent fluid parameters. In Fig.3a, the influence of viscous heating of the fluid on the temperature profile is presented. From the graphical result, an increase in the viscous heating parameter is seen to raise the fluid temperature distribution in the core area of the channel; this is so because the fluid viscosity increases the heat generated due to the frictional interaction of the fluid particles. In Fig. $3 b$, the variation of the fluid temperature with the magnetic field is presented. From the plot, the balanced effect of suction and injection on the fluid is clearly seen. However, as seen in Figs.3c and 3d, increasing values of the couple stress parameter is seen to increase the fluid temperature due to thinning of the fluid. Also, note that the couple stress inverse parameter enhances the fluid temperature. A similar conduct to that is seen as the suction parameter increases. In Figs.3e and 3f, variation of the internal heat loss parameter and Prandtl number are presented, as the heat loss parameter increases, the fluid temperature falls since the heat is dissipated. Lastly, the Prandtl number is seen to decrease the temperature distribution within the domain of flow; this is because the increased Prandtl number is associated with decreased thermal conductivity of the fluid. 


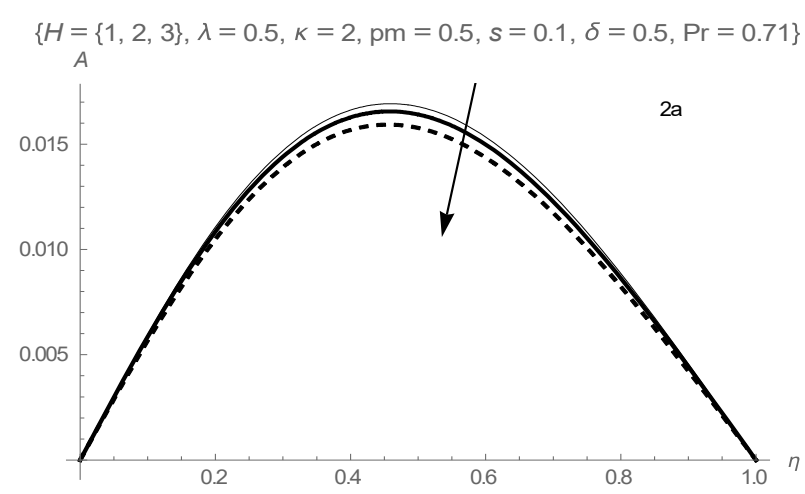

Fig.2a. Variation of steady velocity with the magnetic field parameter.

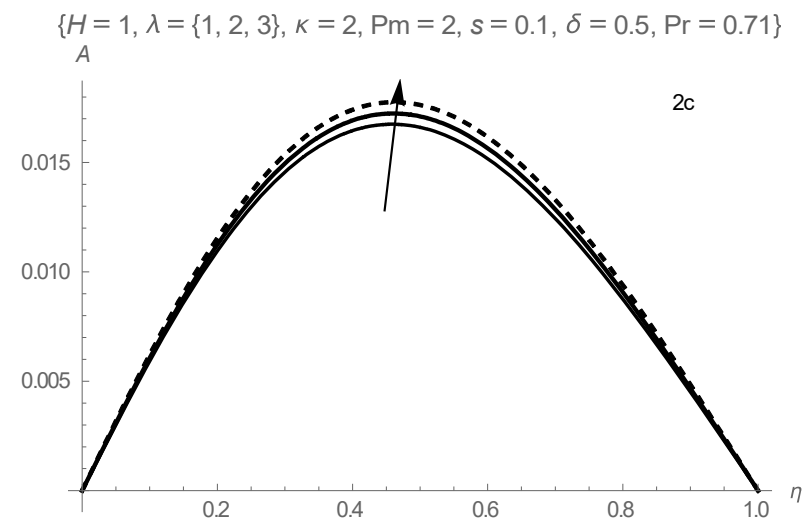

Fig.2c. Variation of steady velocity with the viscous heating parameter.

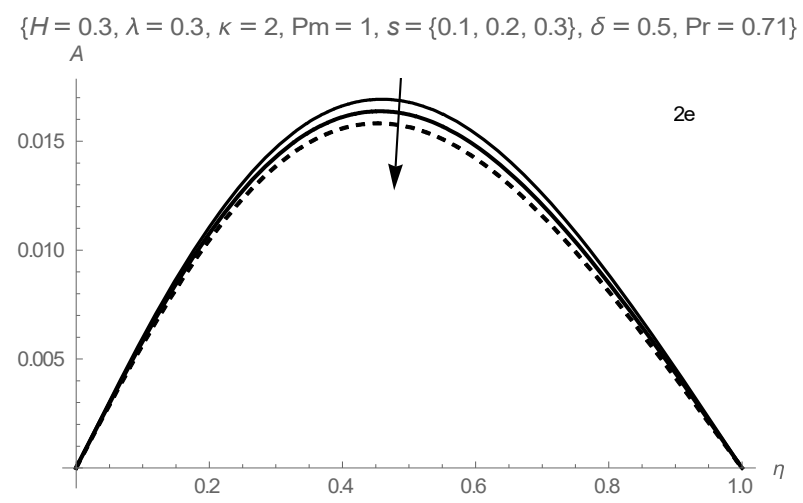

Fig.2e. Variation of steady velocity with the suction Reynolds number.

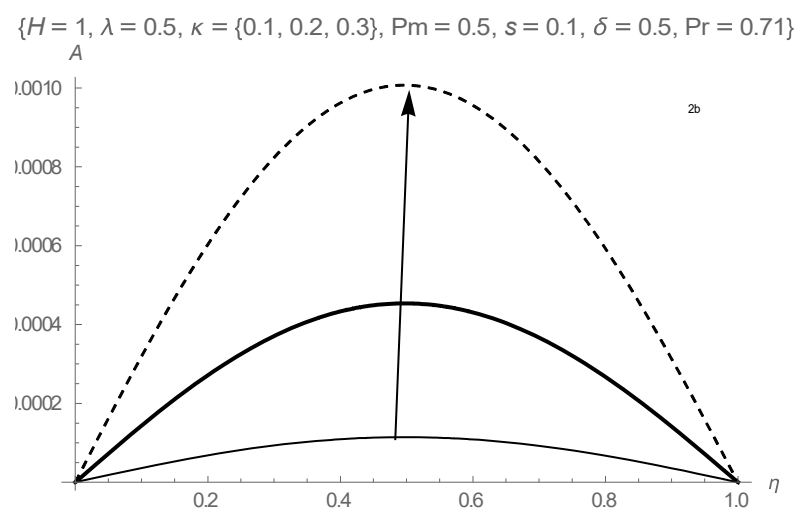

Fig.2b. Variation of steady velocity with the couple stress inverse parameter.

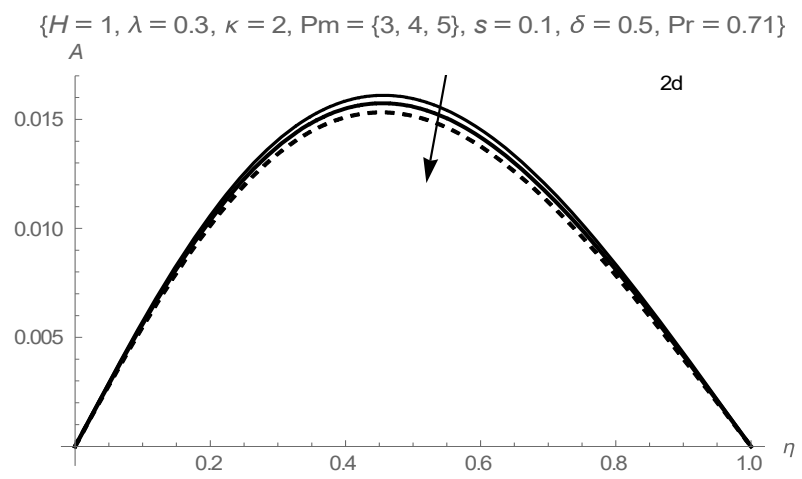

Fig.2d. Variation of steady velocity with the magnetic Prandtl number.

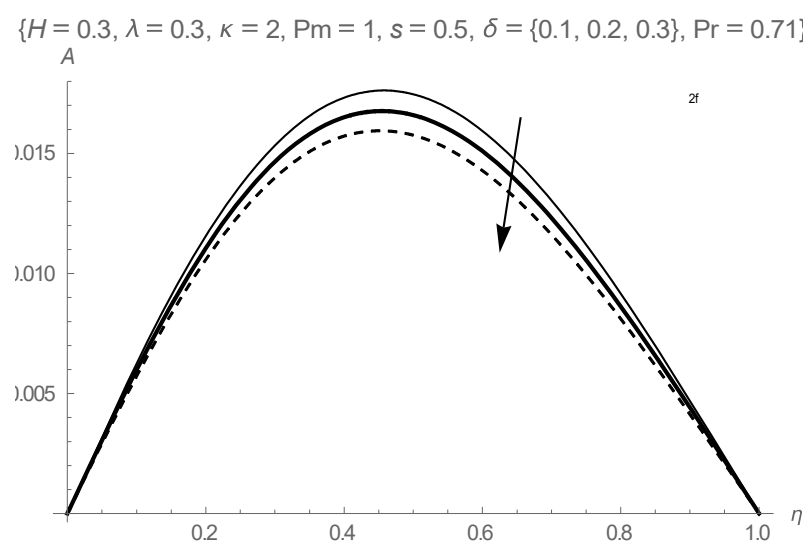

Fig.2f. Variation of steady velocity with the heat sink parameter. 


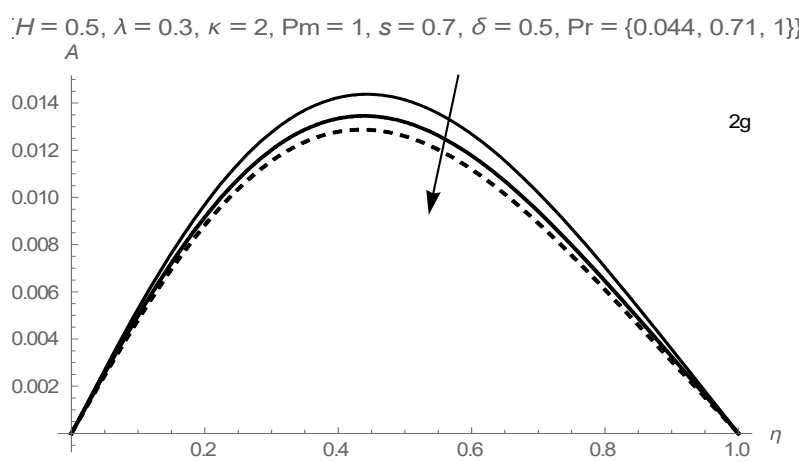

Fig.2g. Variation of steady velocity with the Prandtl number.
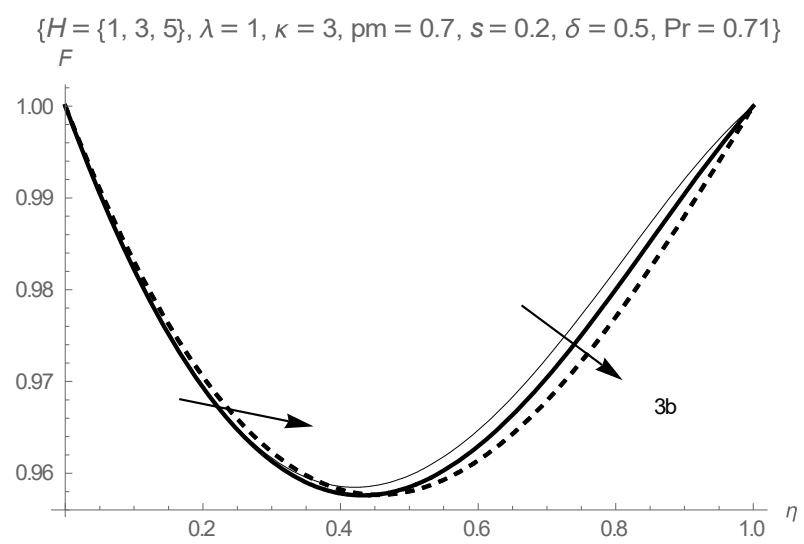

Fig.3b. Variation of steady temperature profile with the magnetic field parameter.

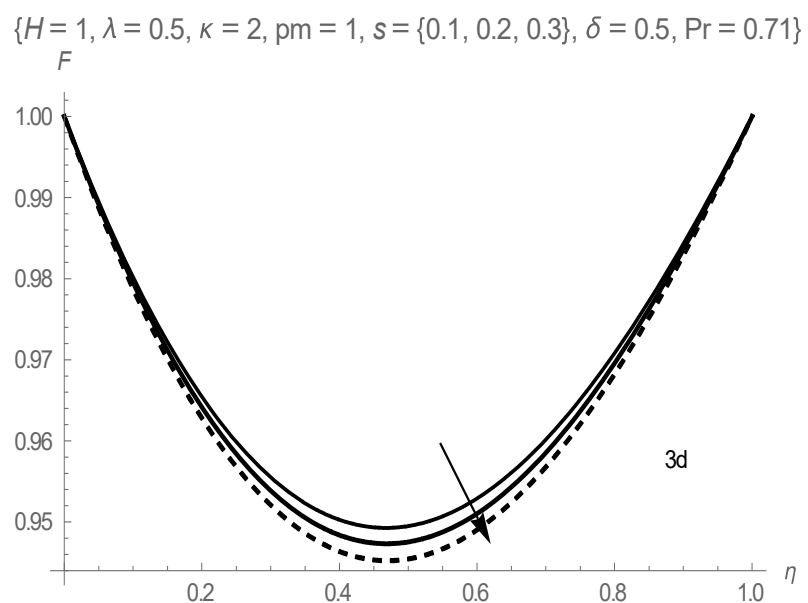

Fig.3d. Variation of steady temperature profile with the suction Reynolds number.
$\{H=1, \lambda=\{0.1,0.2,0.3\}, \kappa=3, \operatorname{Pm}=1, s=0.1, \delta=0.5, \operatorname{Pr}=0.71\}$

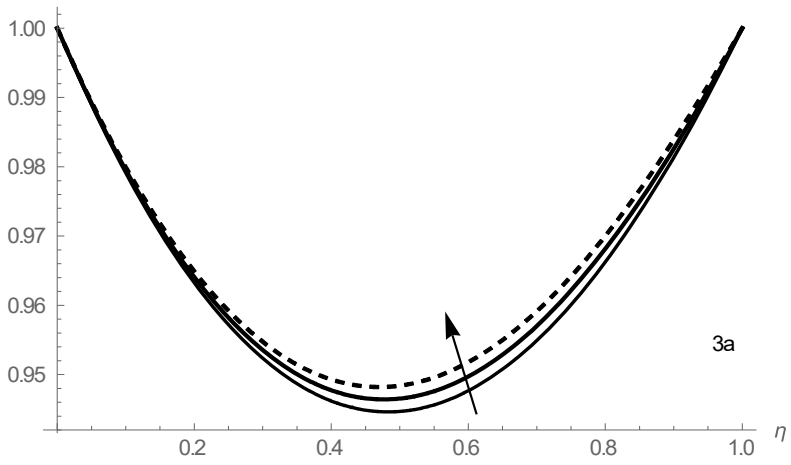

Fig.3a. Variation of steady temperature profile with the viscous heating parameter.

$\left\{\begin{array}{l}H=1, \lambda=0.1, K=\{4,5,6\}, P m=2, s=0.1, \delta=0.5 \\ F\end{array}\right.$

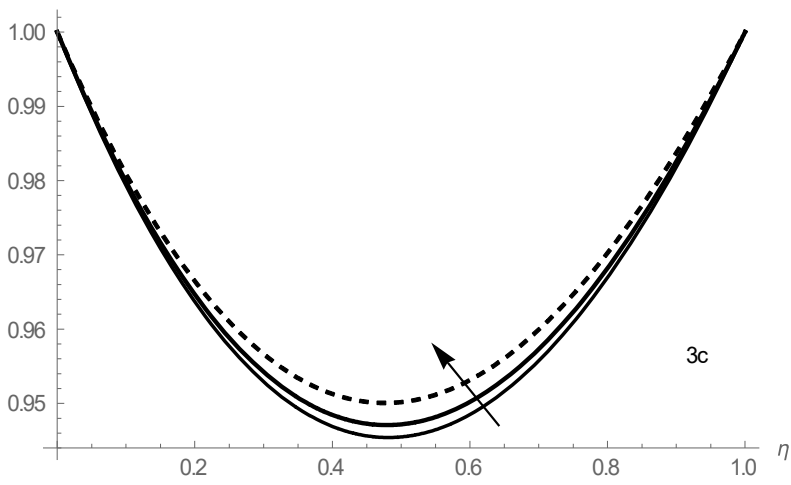

Fig.3c. Variation of steady temperature profile with the couple stress inverse parameter.

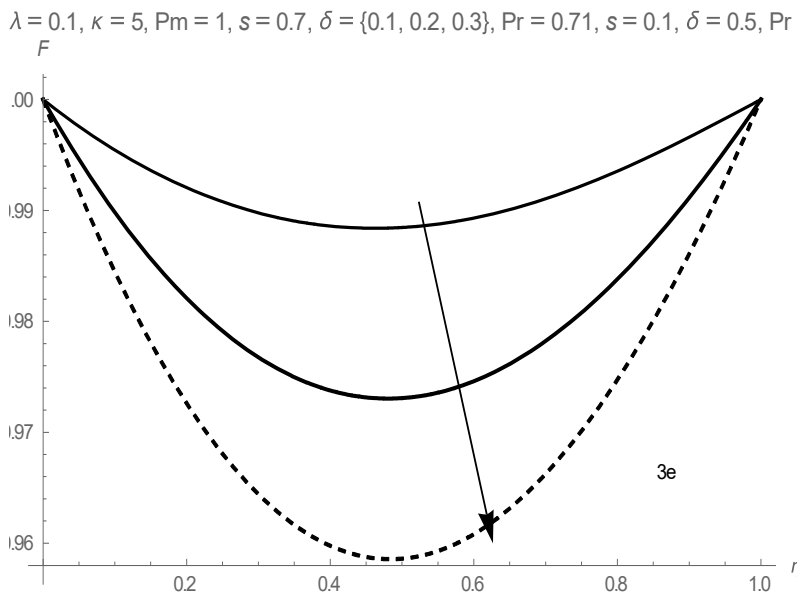

Fig.3e. Variation of steady temperature profile with the internal heat loss parameter. 
$\lambda=0.5, k=1, \operatorname{Pm}=1, s=0.7, \delta=0.5, \operatorname{Pr}=\{0.044,0.71,1\}, s=0.1, \delta=0.5, \operatorname{Pr}$

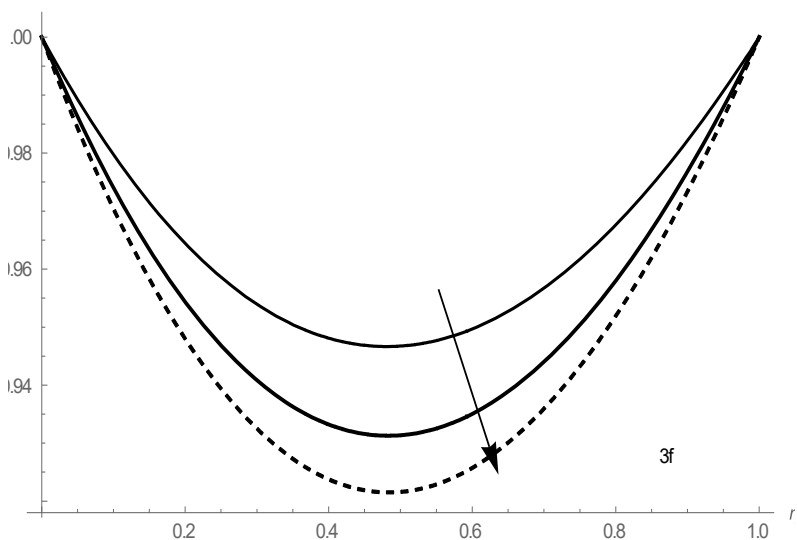

Fig.3f. Variation of steady temperature profile with the Prandtl parameter.

$\{H=3, \lambda=\{0.1,0.5,1\}, K=5, \operatorname{Pm}=2, s=0.3, \delta=0.1, \operatorname{Pr}=0.71\}$

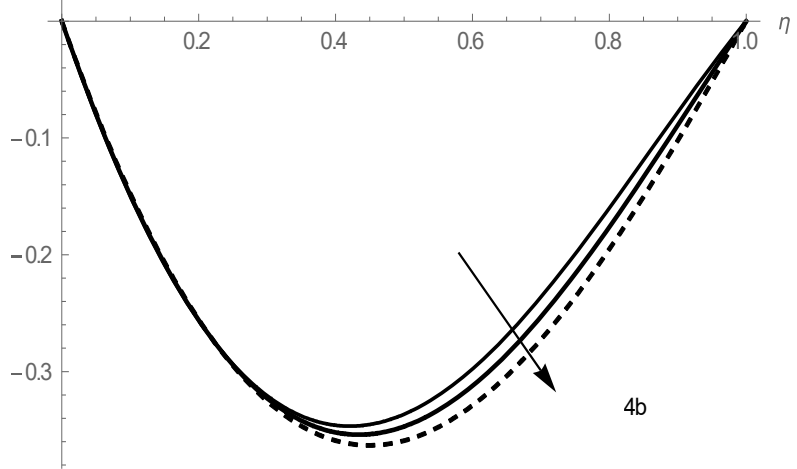

Fig.4b. Variation of steady induced magnetic field with the viscous heating parameter.

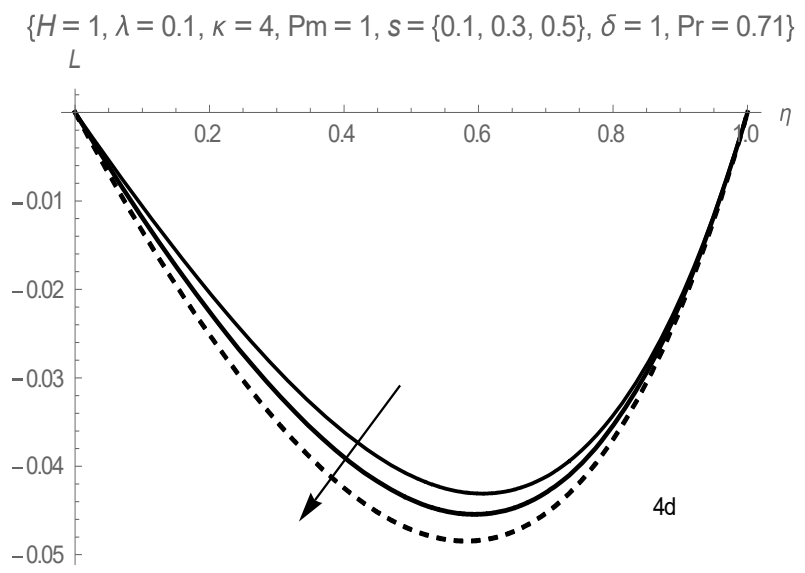

Fig.4d. Variation of steady induced magnetic field with the suction Reynolds number.
$H=\{0.1,0.2,0.3\}, \lambda=0.1, k=1, \operatorname{Pm}=0.3, s=0.5, \delta=1, \operatorname{Pr}=0.71$

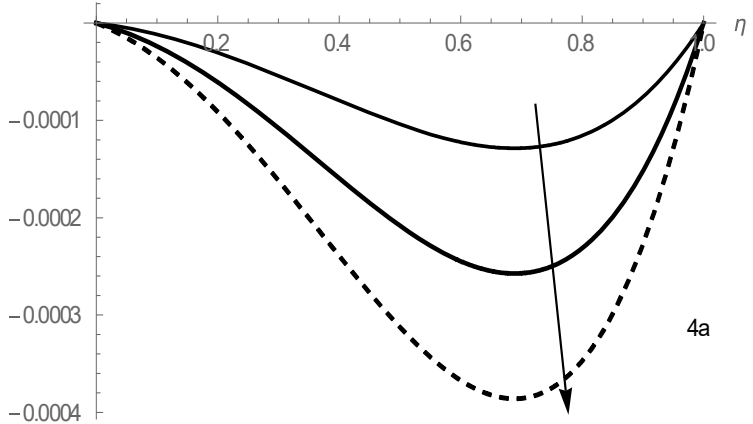

Fig.4a. Variation of steady induced magnetic field with the magnetic field parameter.

$H=1, \lambda=0.1, K=\{0.1,0.2,0.3\}, \operatorname{Pm}=0.3, s=0.5, \delta=1, \operatorname{Pr}=0.71$ L

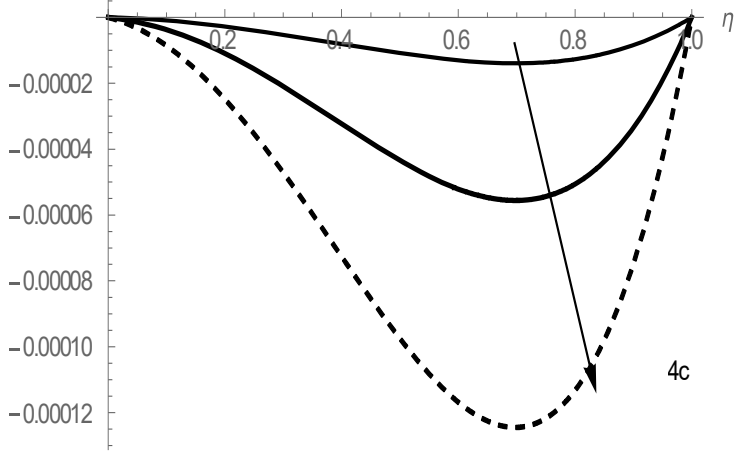

Fig.4c. Variation of steady induced magnetic field with the couple stress inverse parameter.

$\{H=0.3, \lambda=0.1, K=1, \operatorname{Pm}=\{1,2,3\}, s=0.1, \delta=0.1, \operatorname{Pr}=0.71\}$

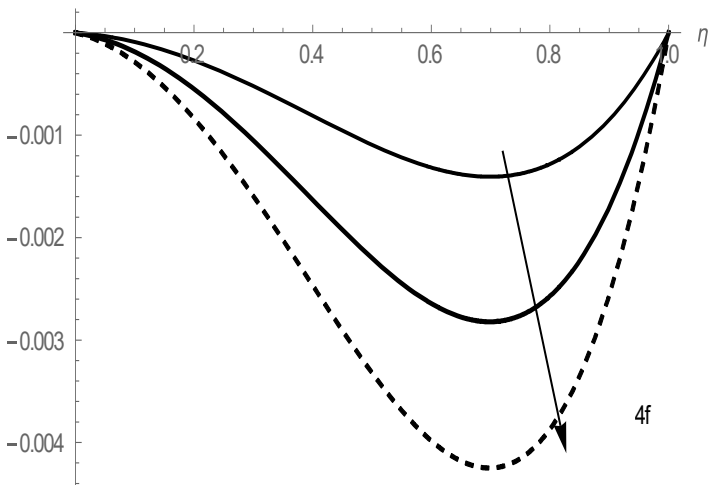

Fig.4f. Variation of steady induced magnetic field with the magnetic Prandtl number. 


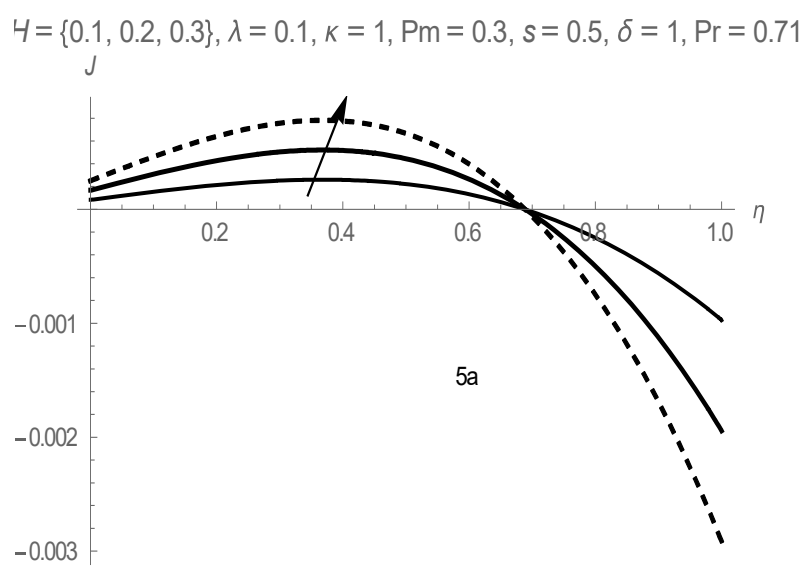

Fig.5a. Variation of steady induced current density with the magnetic field parameter.

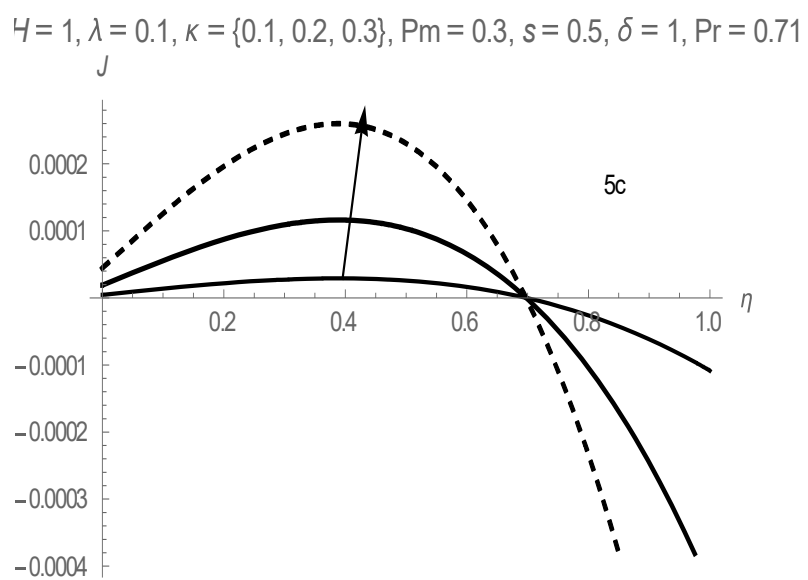

Fig.5c. Variation of steady induced current density with the couple stress inverse parameter.

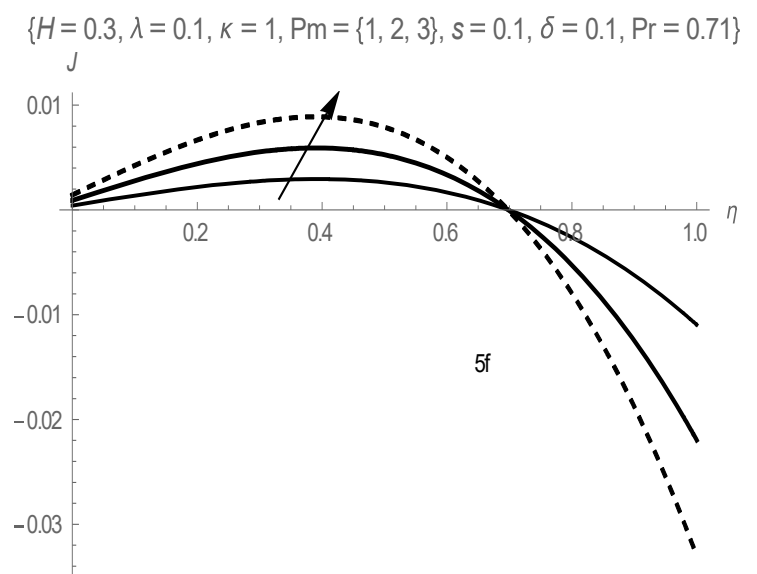

Fig.5f. Variation of steady induced current density with the magnetic Prandtl number.

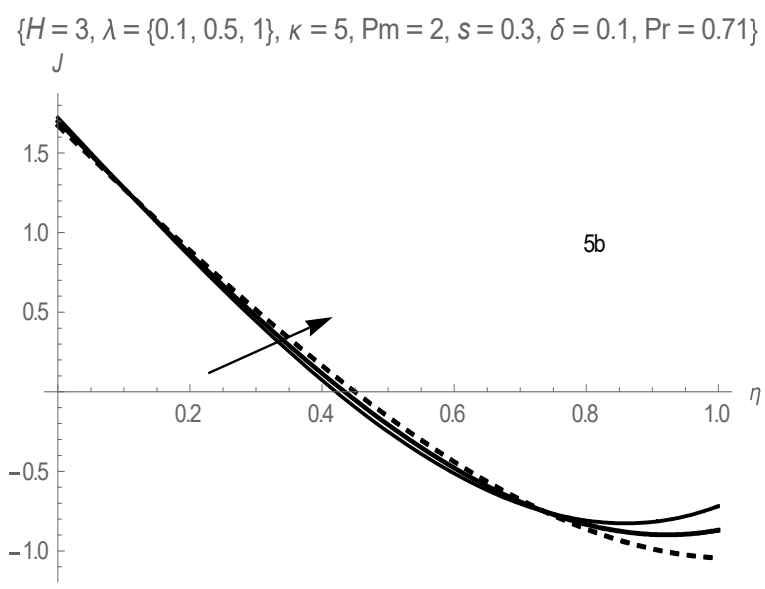

Fig.5b. Variation of steady induced current density with the viscous heating parameter.

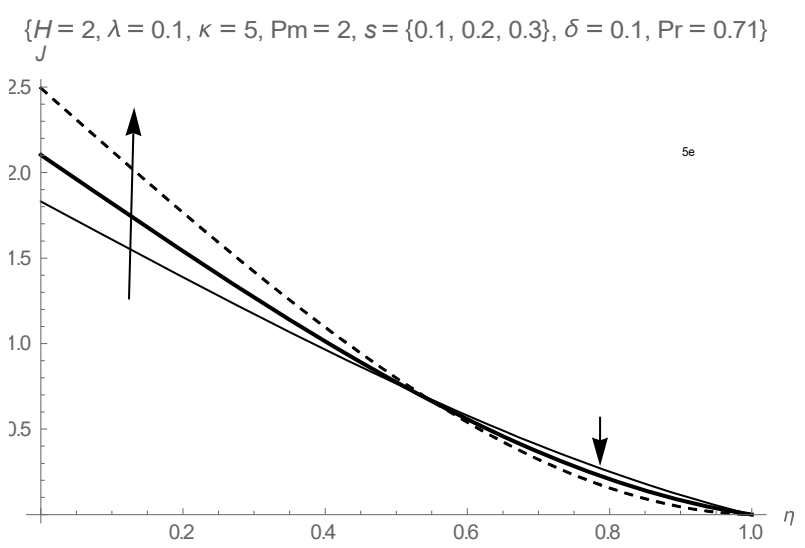

Fig.5d. Variation of steady induced current density with the suction Reynolds number.

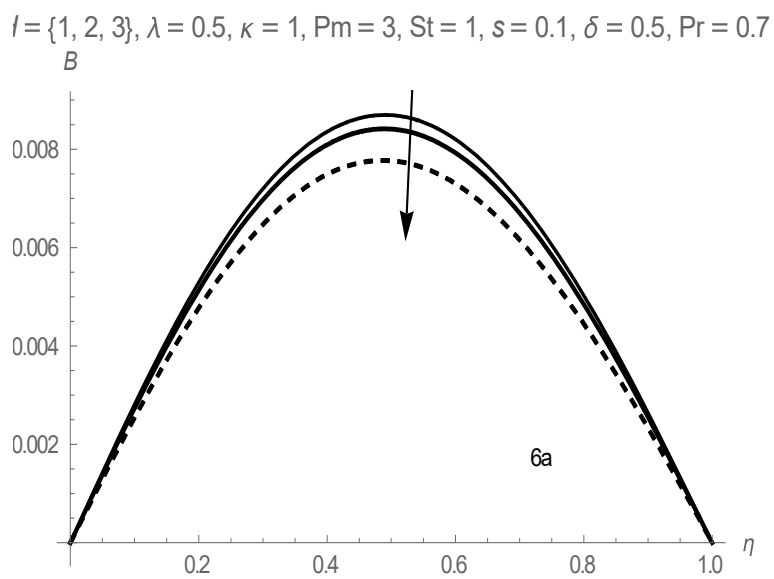

Fig.6a. Variation of oscillatory velocity profile with the magnetic field parameter. 


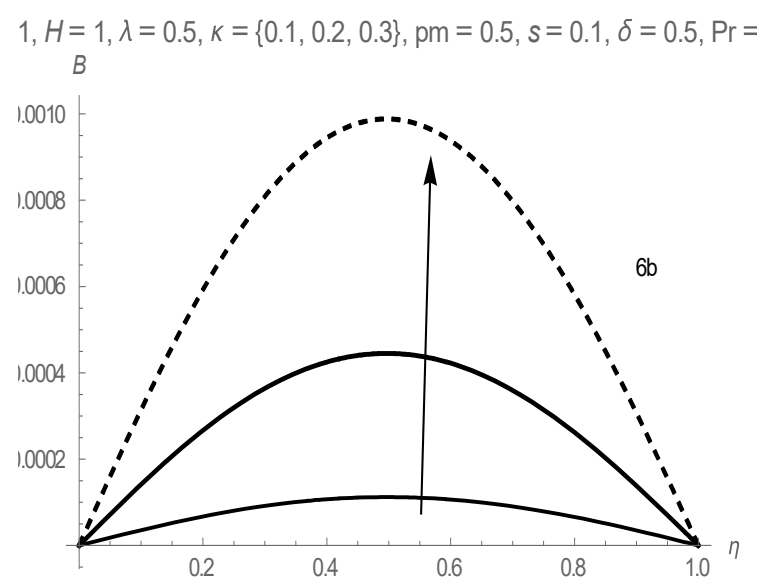

Fig.6b. Variation of oscillatory velocity profile with the couple stress inverse parameter.

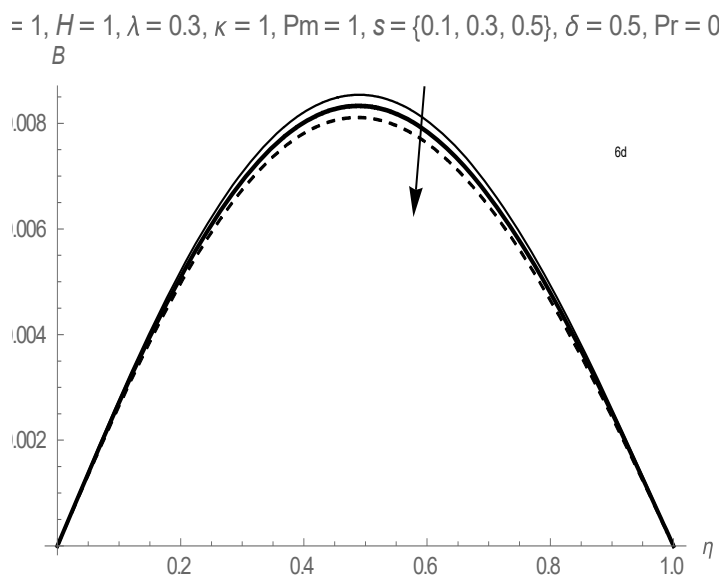

Fig.6d. Variation of oscillatory velocity profile with the suction Reynolds number.

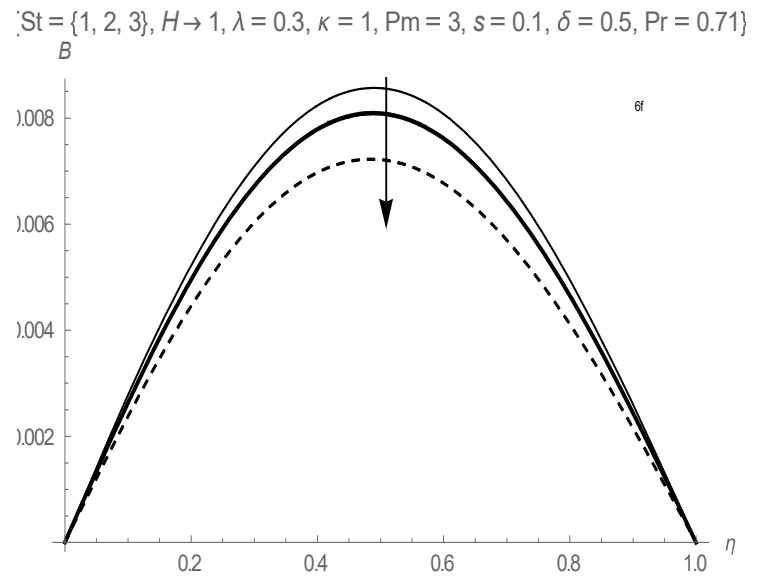

Fig.6f. Variation of oscillatory velocity profile with the Strouhal number.

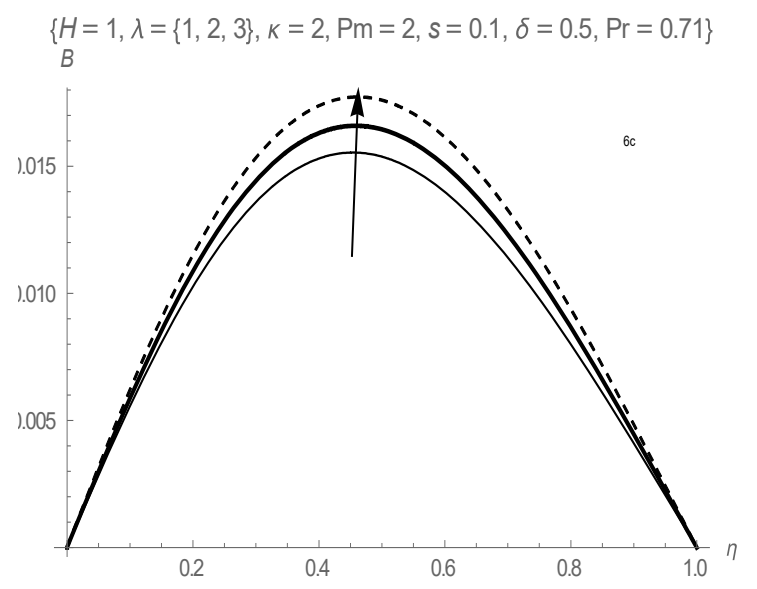

Fig.6c. Variation of oscillatory velocity profile with the viscous heating parameter.

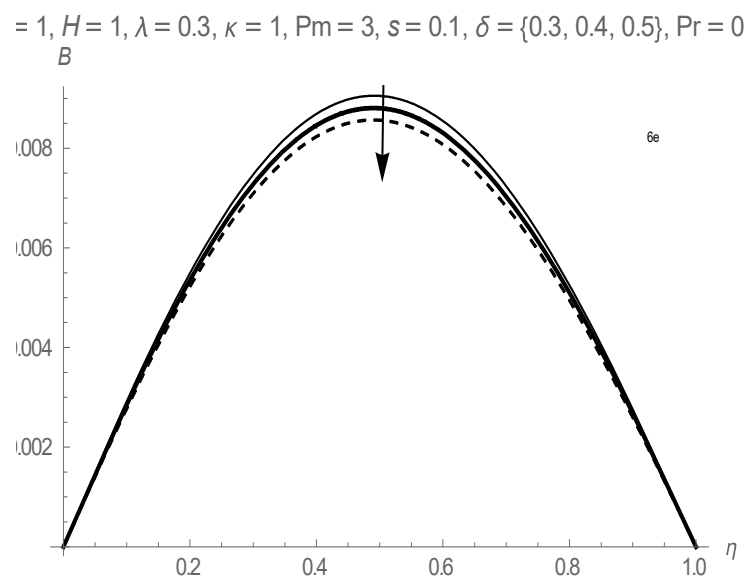

Fig.6e. Variation of oscillatory velocity profile with internal heat loss parameter.

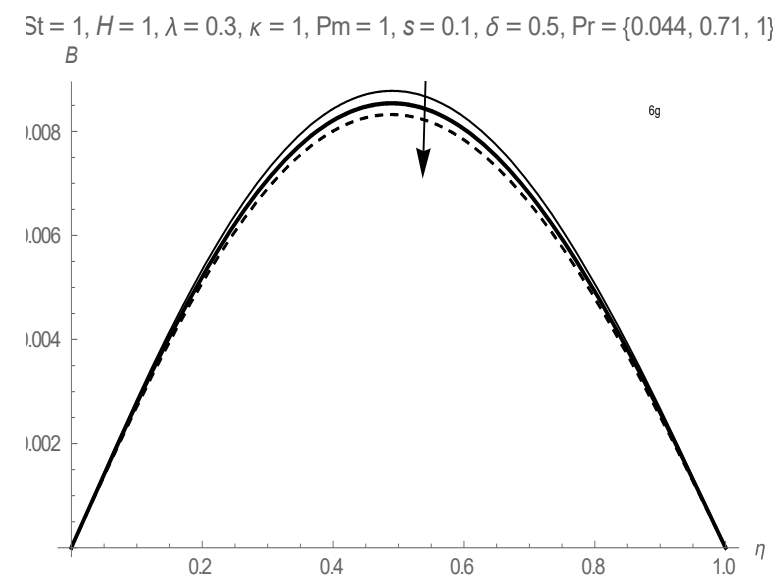

Fig.6g. Variation of oscillatory velocity profile with the Prandtl number. 
$S t \underset{G}{S}\{0.1,0.5,1\}, H=1, \lambda=0.3, \kappa=1, \operatorname{Pm}=3, s=0.1, \delta=0.5, \operatorname{Pr}=0.71\}$

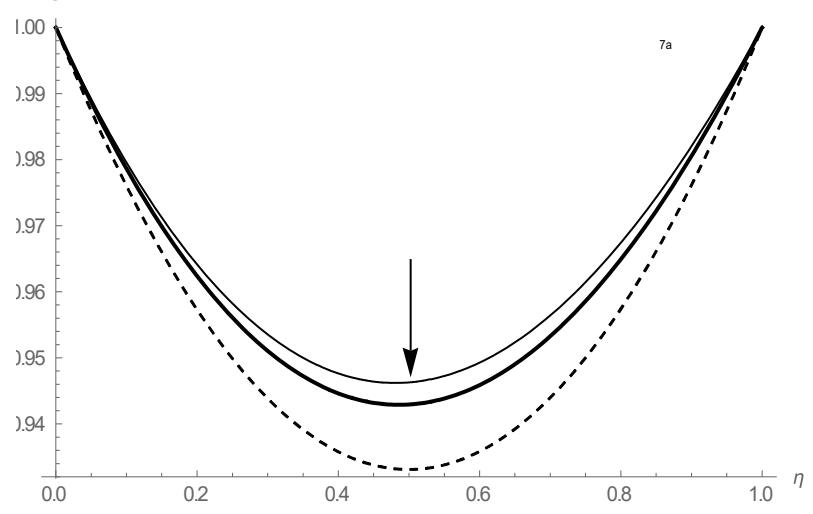

Fig.7a. Variation of unsteady temperature profile with the Strouhal number.

$\underset{G}{\{S t}=1, H=1, \lambda=\{0.1,0.3,0.5\}, K=1, \operatorname{Pm}=1, s=0.1, \delta=0.5, \operatorname{Pr}=0.71\}$

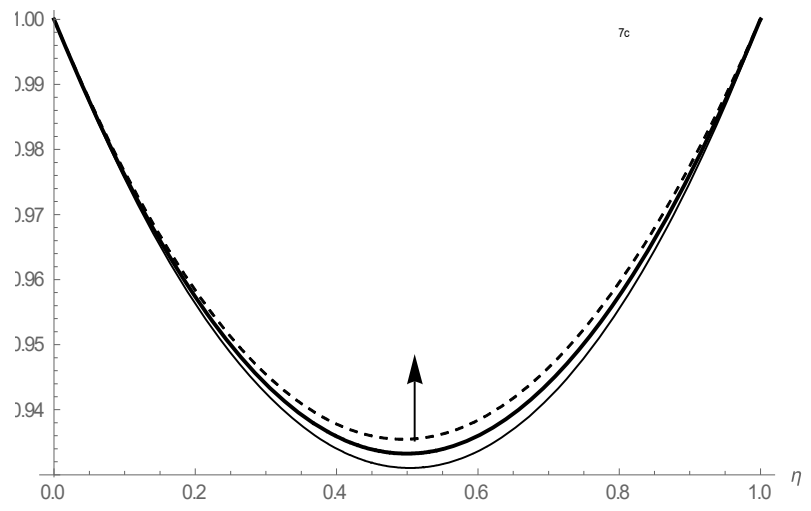

Fig.7c. Variation of unsteady temperature profile with the viscous heating parameter.

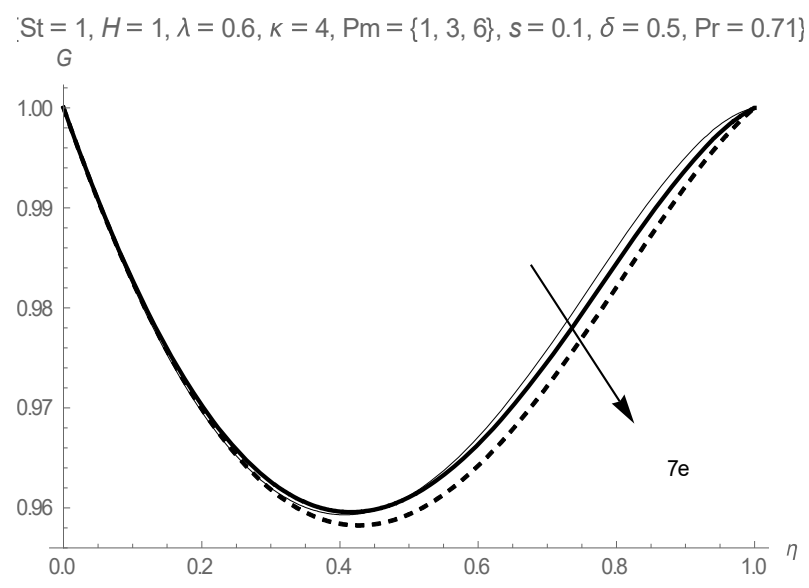

Fig.7e. Variation of unsteady temperature profile with the magnetic Prandtl number.
$\{\mathrm{St}=0.5, H=\{0.1,0.3,0.5\}, \lambda=0.3, \kappa=5, \mathrm{Pm}=3, s=0.1, \delta=0.5, \operatorname{Pr}=0.71\}$

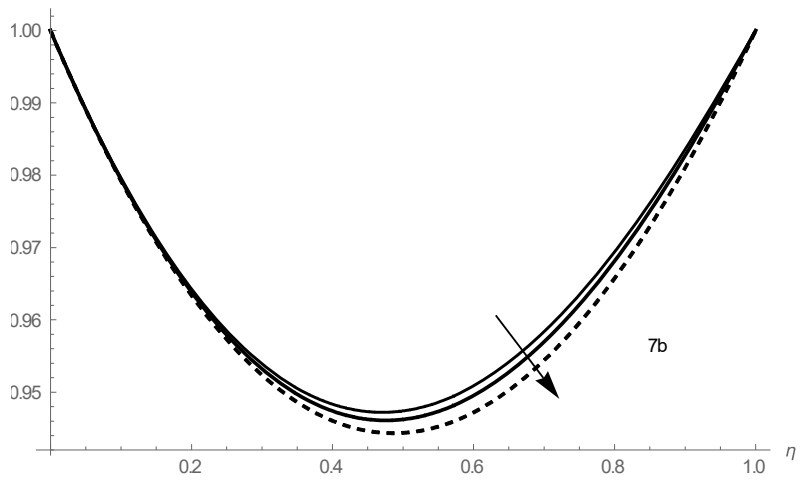

Fig.7b. Variation of unsteady temperature profile with the magnetic field parameter.

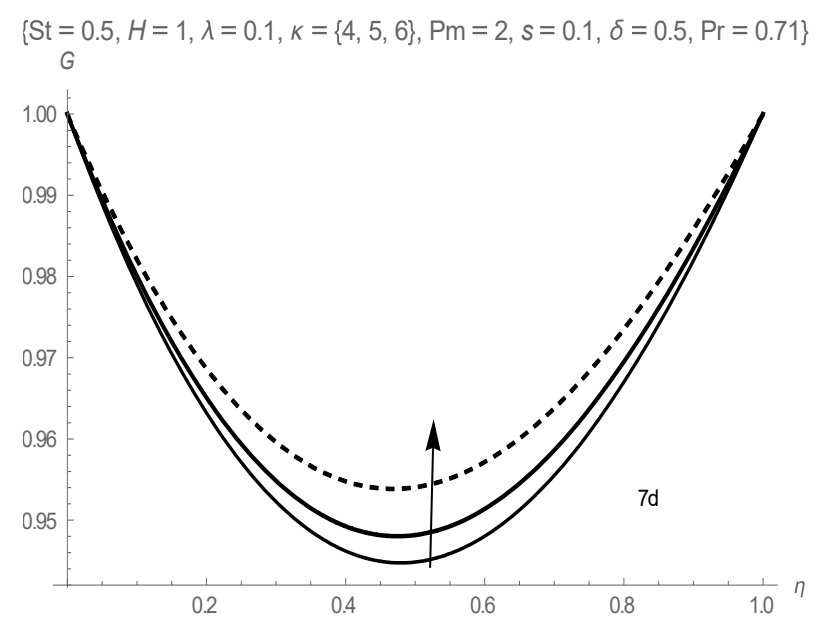

Fig.7d. Variation of unsteady temperature profile with the couple stress inverse parameter.

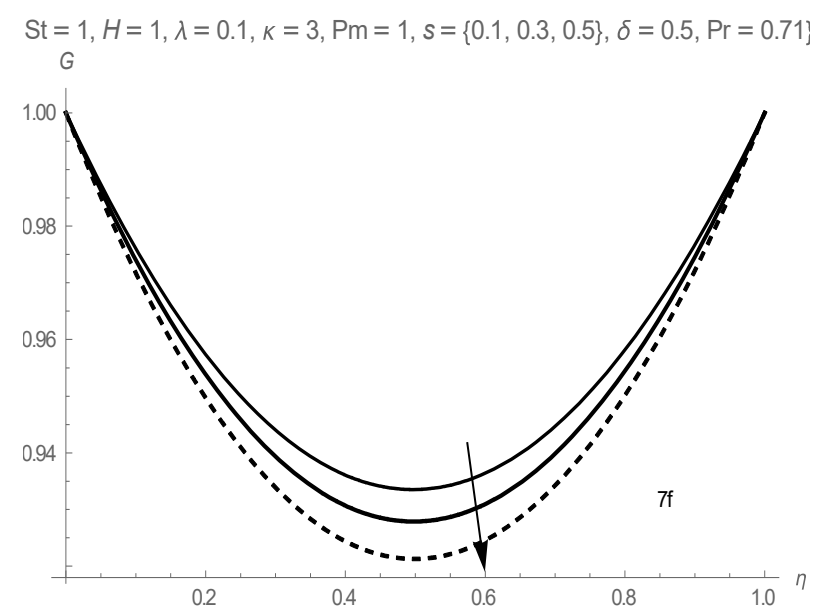

Fig.7f. Variation of unsteady temperature profile with the suction Reynolds number. 


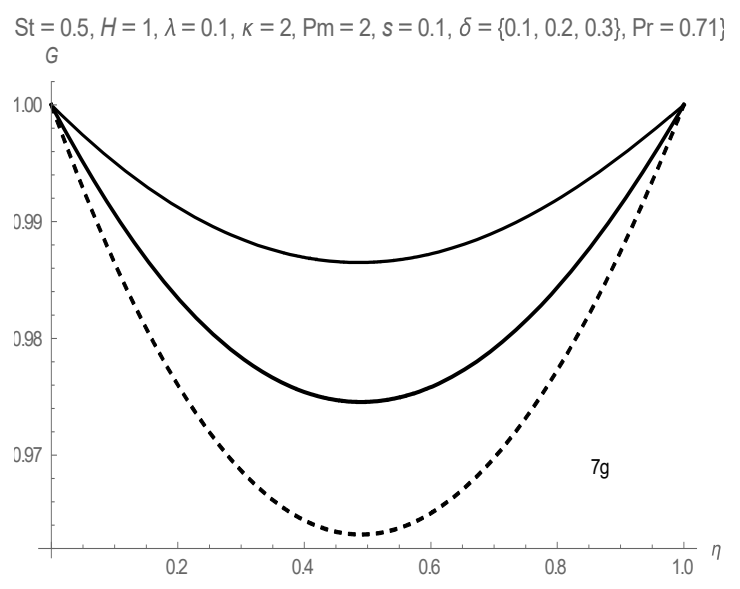

Fig.7g. Variation of unsteady temperature profile with the internal heat loss parameter.

$\mathrm{St}=\{1,2,3\}, H=1, \lambda=0.1, K=1, \operatorname{Pm}=1, s=0.1, \delta=0.5, \operatorname{Pr}=0.71\}$

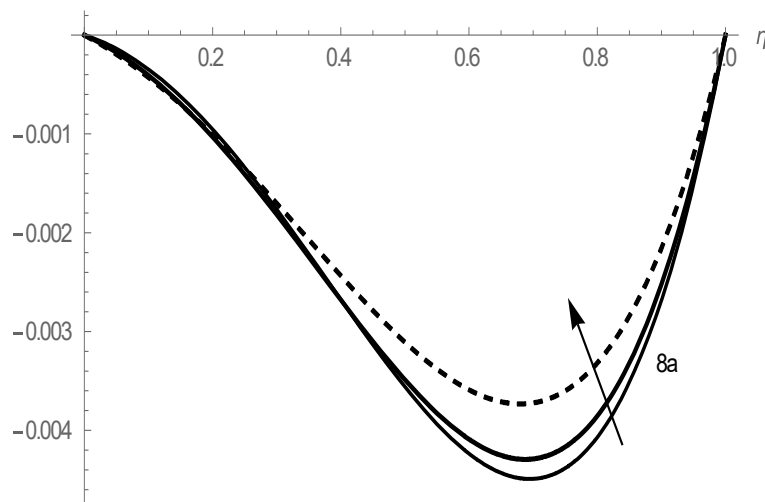

Fig.8a. Variation of unsteady induced magnetic field with the Strouhal number.

$\{H=2, \lambda=\{0.01,0.5,1\}, \kappa=5, \operatorname{Pm}=2, s=0.1, \delta=0.5, \operatorname{Pr}=0.71\}$

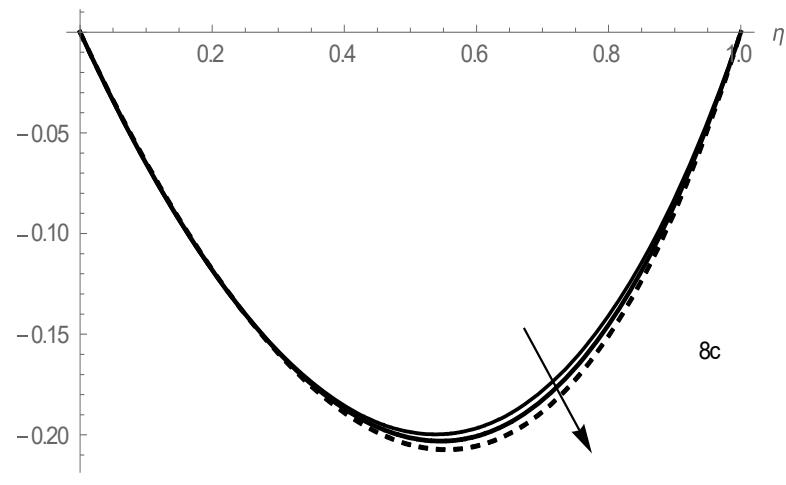

Fig.8c. Variation of unsteady induced magnetic field with the viscous heating parameter.

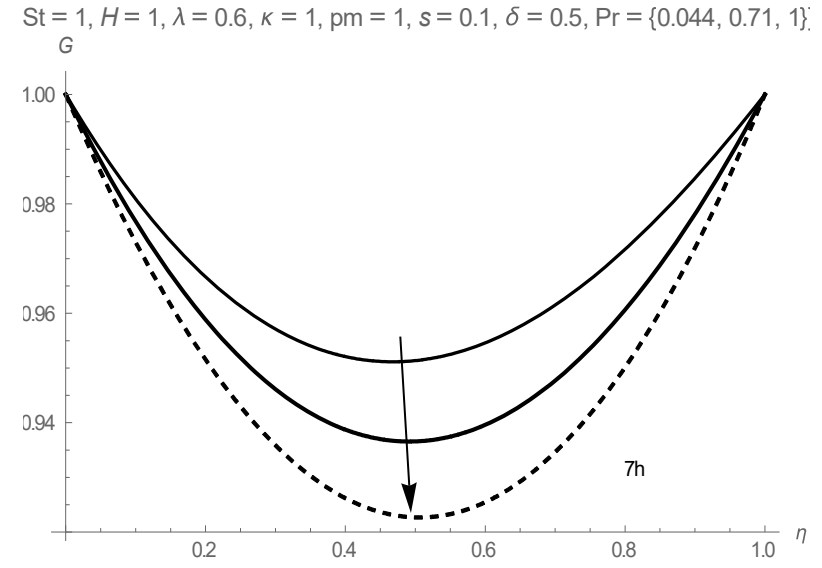

Fig.7h. Variation of unsteady temperature profile with the Prandtl number.

$\mathrm{St}=1, H=\{0.1,0.2,0.3\}, \lambda=0.1, k=1, \mathrm{Pm}=1, s=0.1, \delta=0.5, \mathrm{Pr}=0.71\}$

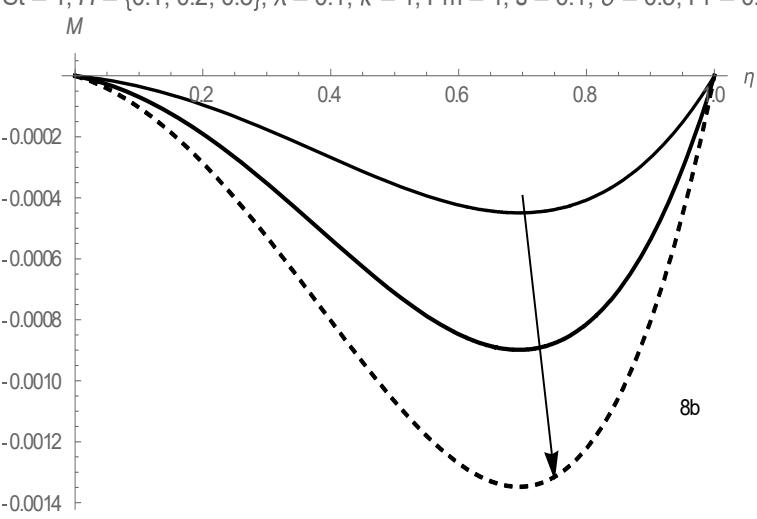

Fig. $8 \mathrm{~b}$. Variation of unsteady induced magnetic field with the magnetic field parameter.

St $=1, H=1, \lambda=0.1, K=\{0.1,0.2,0.3\}, \operatorname{Pm} \rightarrow 2, s=0.1, \delta=0.5, \operatorname{Pr}=0.71$ M

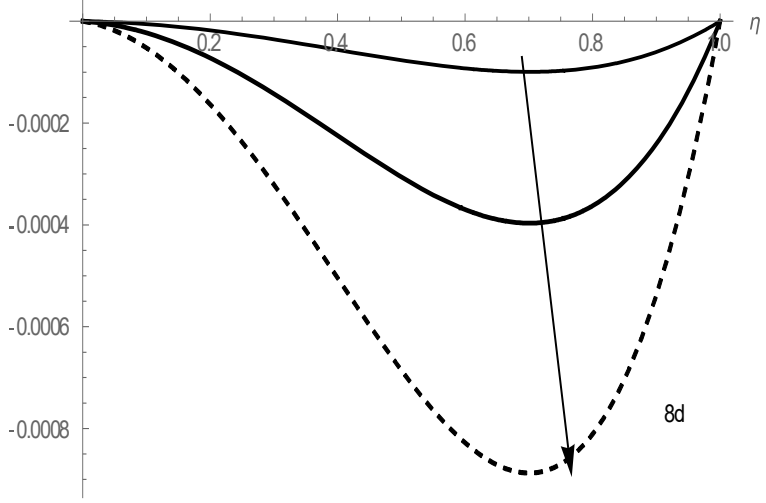

Fig.8d. Variation of unsteady induced magnetic field with the couple stress inverse parameter. 


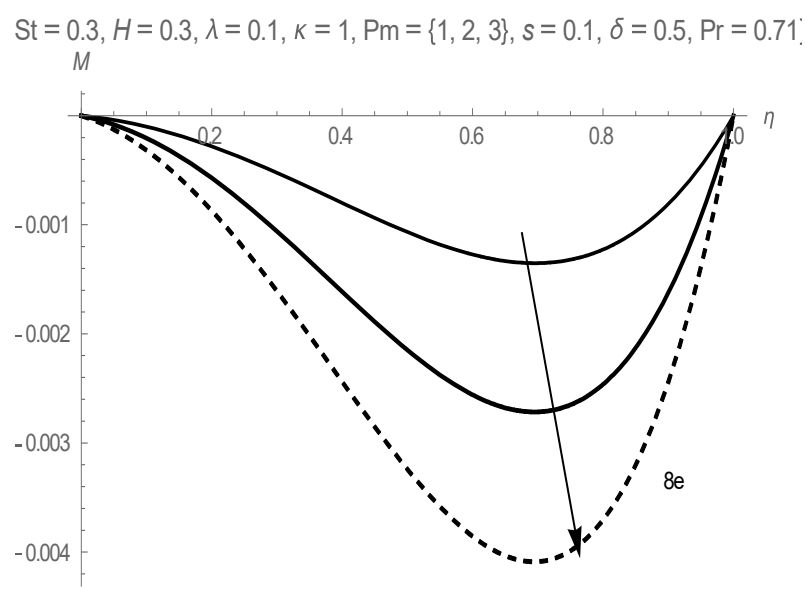

Fig.8e. Variation of unsteady induced magnetic field with the magnetic Prandtl number.

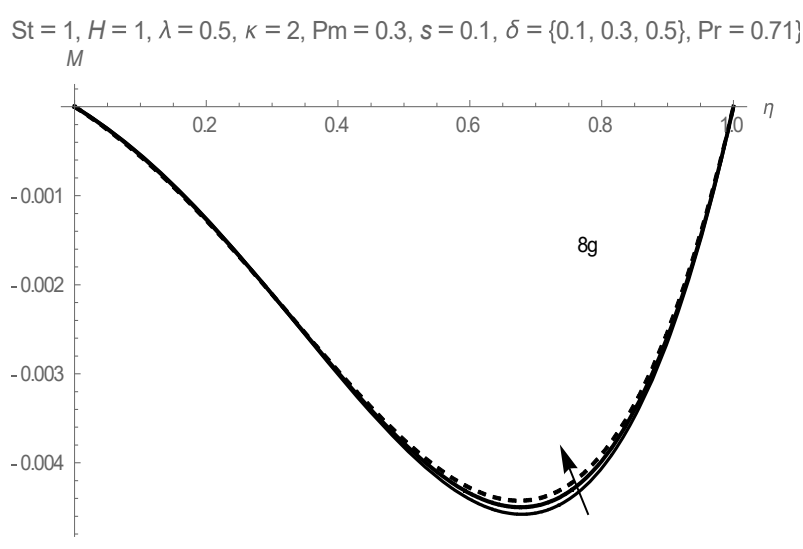

Fig.8g. Variation of unsteady induced magnetic field with the internal heat loss parameter.

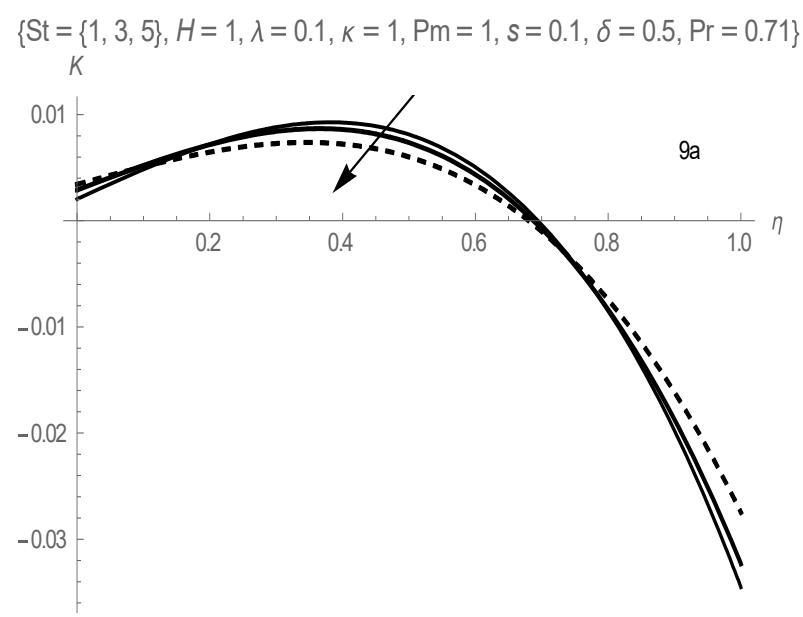

Fig.9a. Variation of unsteady current density profile with the Strouhal number.

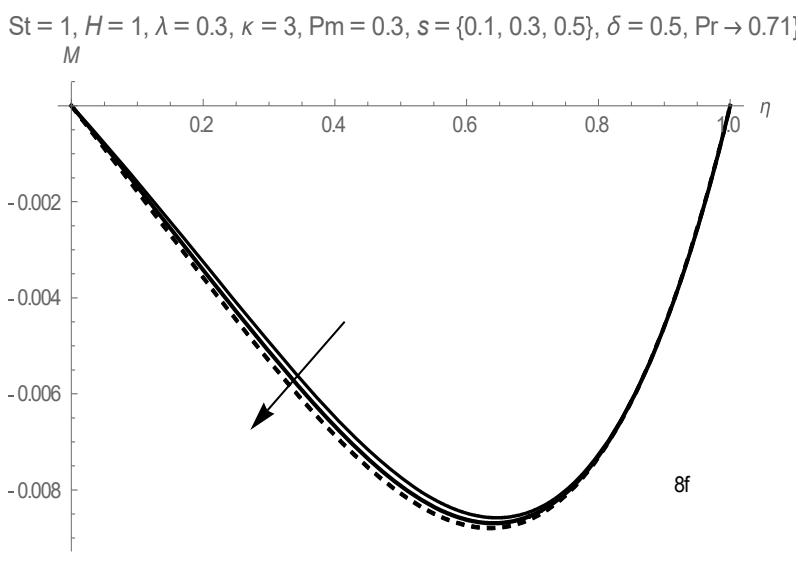

Fig.8f. Variation of unsteady induced magnetic field with the suction Reynolds number.

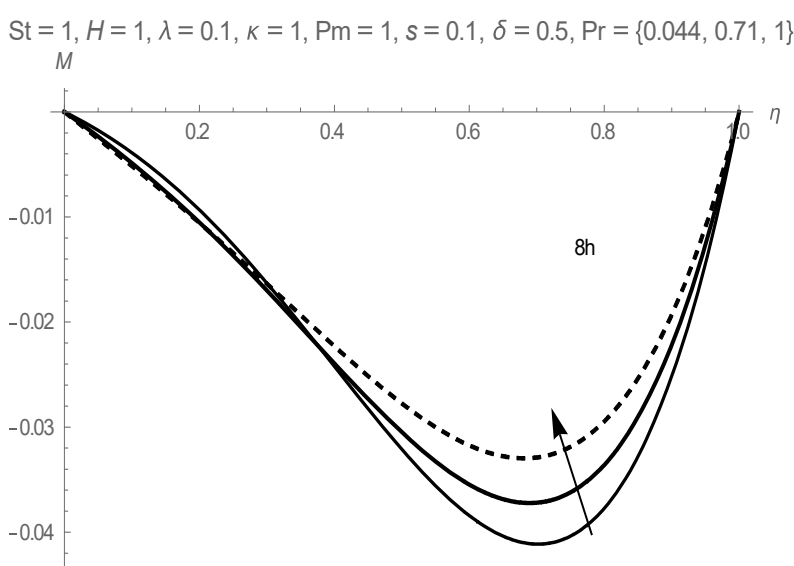

Fig.8h. Variation of unsteady induced magnetic field with the Prandtl number.

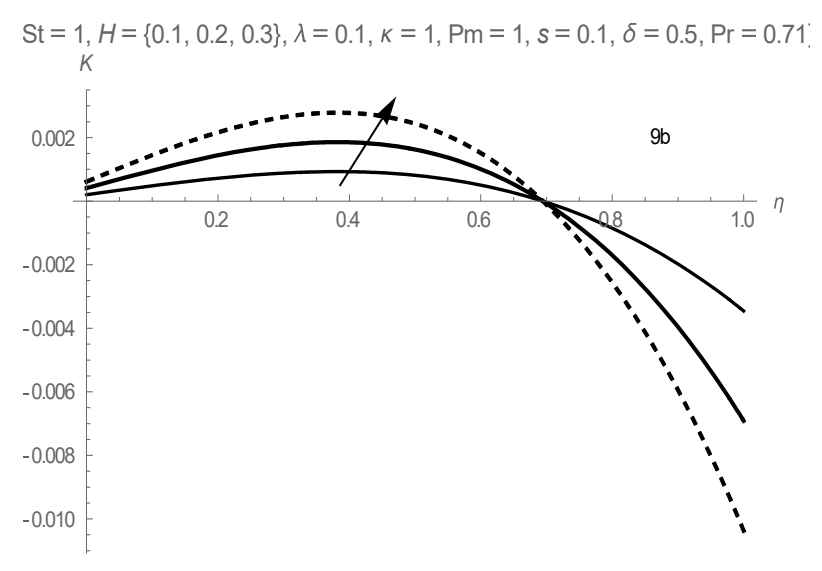

Fig.9b. Variation of unsteady current density profile with the magnetic field parameter. 


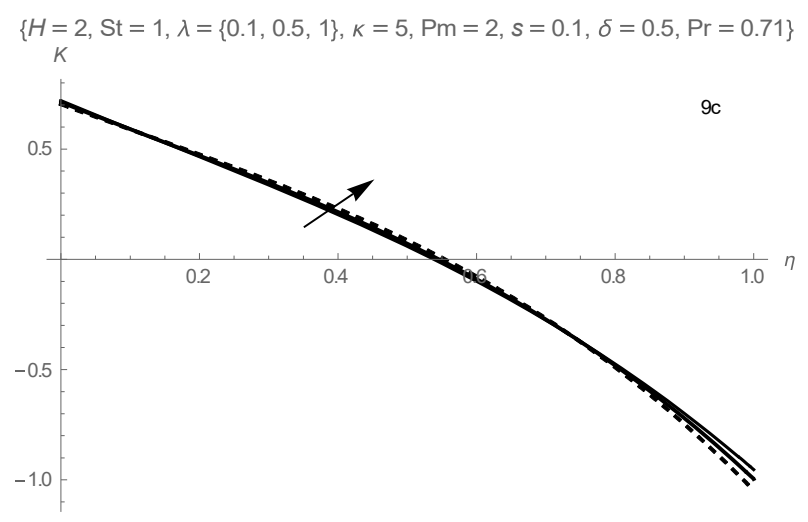

Fig.9c. Variation of unsteady current density profile with the viscous heating parameter.

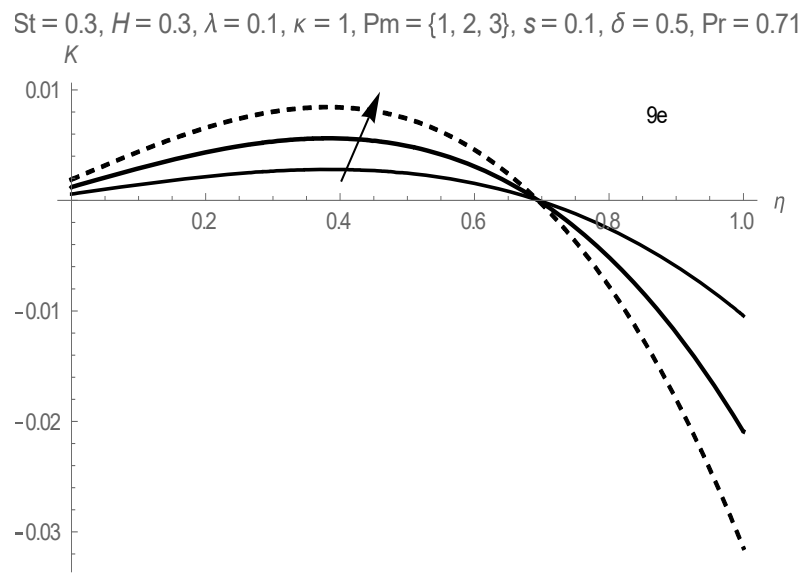

Fig.9e. Variation of unsteady current density profile with the magnetic Prandtl number.

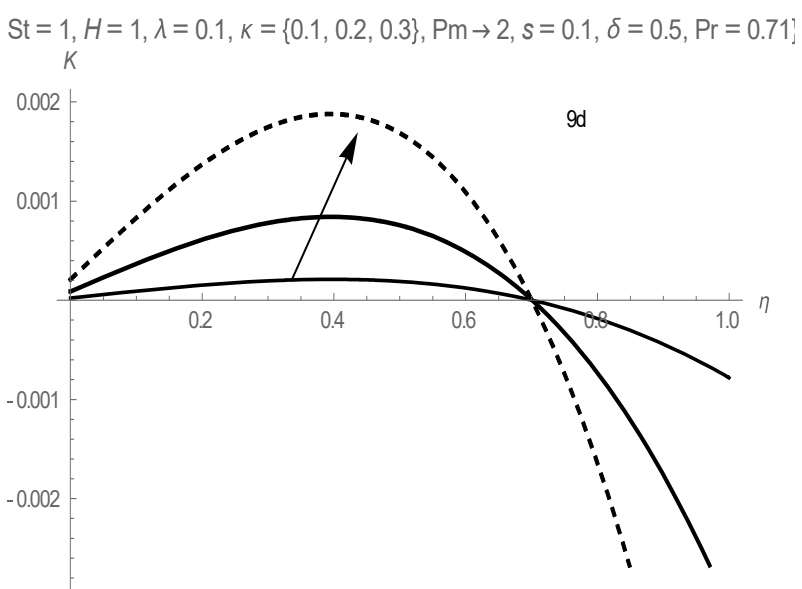

Fig.9d. Variation of unsteady current density profile with the couple stress inverse parameter.

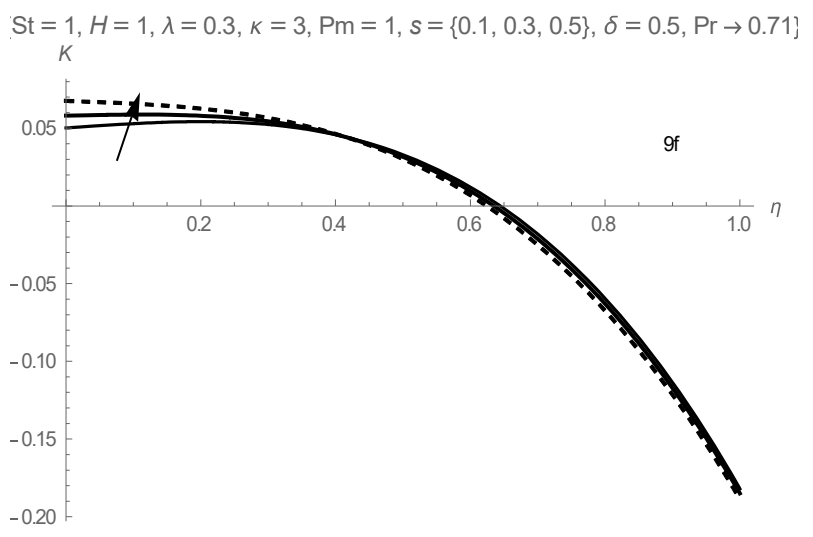

Fig.9f. Variation of unsteady current density profile with the suction Reynolds number.

Figures 4 addresses the response of the induced magnetic field to the variation of fluid parameters. It is important to see that Figs $4 \mathrm{a}-4 \mathrm{f}$ are all negative due to the flow reversal of the magnetic flux in the channel. On the other hand, the induced current density shown in Figs 5 represents the induced current density which is a direct opposite presentation to the induced magnetic field. Conclusion concerning the results in Figs 6-9 for the unsteady flow behaviour are seen to conform with the steady case except for reduction in the flow and heat maximum that is associated with increased frequency of heating as highlighted in Figs $5 \mathrm{f}, 6 \mathrm{f}$ and $7 \mathrm{a}$.

\section{Conclusions}

The convective flow of a hydromagnetic couple stress fluid with an induced magnetic field has been addressed here in the steady-periodic regimes. The momentum, energy and magnetic induction equations are formulated, made dimensionless and solved by the Adomian decomposition method. The main contributions to of the present study are as follows:

- Increasing values of the Hartman number, Strouhal number, couple stress parameter and heat loss parameter decrease the flow velocity while viscous heating of the fluid encourages both steady and oscillatory flow profiles. 
- Fluid temperature distribution is seen to improve with increasing values of the viscous heating parameter, Hartman number, and the couple stress parameter while it decreases with increasing values of the Prandtl number, heat loss parameter, suction parameter and Strouhal number.

- Increasing values of the Hartman number, viscous heating, suction and magnetic Prandtl number are seen to enhance the induced current density while an increase in the Strouhal number decreases it.

\section{Nomenclature}

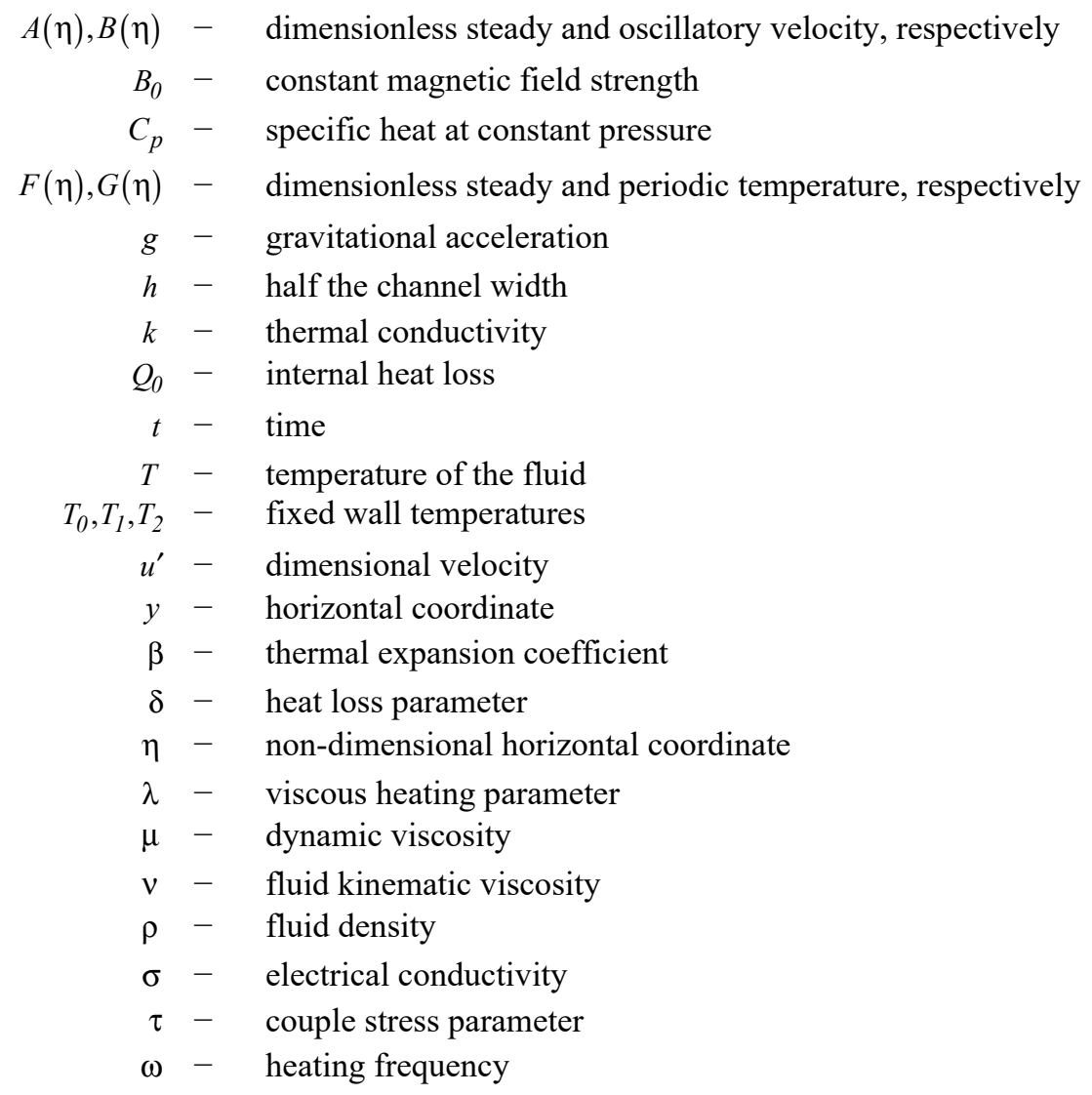

\section{References}

[1] Wang CY. (1988): Free convection between vertical plates with periodic heat input.- ASME J. Heat Trans, vol.110, pp.508-511.

[2] Jha B.K. and Ajibade A.O. (2012): Effect of viscous dissipation on natural convection flow between vertical parallel plates with time-periodic boundary conditions.- Commun. Nonlinear Sci. Numer. Simul., vol.17, pp.1576-1587.

[3] Jha B.K. and Ajibade A.O. (2009): Free convective flow of heat generating/absorbing fluid between vertical porous plates with periodic heat input.- Int. Commun. Heat Mass Transfer, vol.36, pp.624-631.

[4] Jha B.K. and Ajibade A.O. (2010): Free convective flow between vertical porous plates with periodic heat input.ZAMM. J. of Appl. Math. and Mech., pp.1-9. http://dx.doi.org/10.1002/zamm.200900268.

[5] Adesanya S.O. (2015): Free convective flow of heat generating fluid through a porous vertical channel with velocity slip and temperature jump.- Ain Shams Eng. J., vol.6, pp.1045-1052.

[6] Adesanya S.O., Oluwadare E.O., Falade J.A. and Makinde O.D. (2015): Hydromagnetic natural convection flow between vertical parallel plates with time-periodic boundary conditions.- J. Magn. Magn. Mater., vol.396, pp.295-303. 
[7] Abbas Z., Wang Y., Hayat T. and Oberlack M. (2008): Hydromagnetic flow in a viscoelastic fluid due to the oscillatory stretching surface.- Int. J. Non Linear Mech, vol.43, No.8, pp.783-793.

[8] Hayat T., Noreen S., Shabab Alhothuali M., Asghar S. And Alhomaidan A. (2012): Peristaltic flow under the effects of an induced magnetic field and heat and mass transfer.- Int. J. Heat Mass Transfer, vol.55, pp.443-452.

[9] Hayat T., Wang. Y. and Hutter K. (2004): Hall effects on the unsteady hydromagnetic oscillatory flow of a secondgrade fluid.- Int. J. Non Linear Mech., vol.39, pp.1027-1037.

[10] Mehmood A. and Ali A. (2007): The effect of slip condition on unsteady MHD oscillatory flow of a viscous fluid in a planer channel.- Rom J Phys., vol.52, pp.85-91.

[11] Wang C.Y. (1988): Nonlinear streaming due to the oscillatory stretching of a sheet in a viscous.- Acta Mech, vol.72, pp.261-268.

[12] Ahmed S. (2010): Induced magnetic field with radiating fluid over a porous vertical plate: analytical study.- J. Nav. Archit. Mar. Eng., vol.7, pp.83-94.

[13] Raju M.C., Varma S.V.K. and Seshaiah B. (2015): Heat transfer effects on a viscous dissipative fluid flow past a vertical plate in the presence of induced magnetic field.- Ain Shams Eng. J., vol.6, pp.333-339.

[14] Iqbal Z., Ehtsham Azhar. and Maraj E.N. (2017): Transport phenomena of carbon nanotubes and bioconvection nanoparticles on stagnation point flow in presence of induced magnetic field.- Physica E., vol.91, pp.128-135.

[15] Animasaun I.L., Raju C.S.K. and Sandeep N. (2016): Unequal diffusivities case of homogeneous -heterogeneous reactions within viscoelastic fluid flow in the presence of induced magnetic-field and nonlinear thermal radiation.AEJ, vol.55, pp.595-1606.

[16] Sheikholeslami M., Zaigham Zia Q.M. and Ellahi R. (2016): Influence of induced magnetic field on free convection of nanofluid considering Koo-Kleinstreuer-Li (KKL) correlation.- Appl. Sci., vol.6, p.324, doi:10.3390/app6110324.

[17] Noreen S., Hayat T. and Alsaedi A. (2011): Study of slip and induced magnetic field on the peristaltic flow of pseudoplastic fluid.- Int J Phys Sci., vol.6, No.36, pp.8018-8026.

[18] Kumar D. and Singh A.K. (2016): Effects of heat source/sink and induced magnetic field on natural convective flow in vertical concentric annuli.-AEJ, vol.55, pp.3125-3133.

[19] Ghosh S.K., Anwar Bég O. and Zueco J. (2010): Hydromagnetic free convection flow with induced magnetic field effects.- Meccanica, vol.45, pp.175-185.

[20] Raju C.S.K., Sandeep N. and Saleem S. (2016): Effects of induced magnetic field and homogeneous-heterogeneous reactions on stagnation flow of a Casson fluid.- Eng. Sci. Technol., an International Journal, vol.19, pp.875-887.

[21] Kumar A., Singh A.K. (2013): Unsteady MHD free convective flow past a semi-infinite vertical wall with induced magnetic field.- Appl. Math. Comput., vol.222, pp.462-471.

[22] Sheikholeslami M. and Ganji D.D. (2016): Nanofluid hydrothermal behavior in existence of Lorentz forces considering Joule heating effect.- J. Mol. Liq., vol.224, pp.526-537.

[23] Mehmood Z. and Iqbal Z. (2016): Interaction of induced magnetic field and stagnation point flow on bioconvection nanofluid submerged in gyrotactic microorganisms.- J. Mol. Liq., vol.224(A), pp.1083-1091.

[24] Nandya S.K., Tapas Ray Mahapatra and Ioan Pop. (2015): Unsteady separated stagnation-point flow over a moving porous plate in the presence of a variable magnetic field.- Eur. J. Mech. B. Fluids, vol.53, pp.229-240.

[25] Kataria H.R., Patel H.R. and Singh R. (2017): Effect of magnetic field on unsteady natural convective flow of a micropolar fluid between two vertical walls.- Ain Shams Eng. J., vol.8, pp.87-102.

[26] Ojjela O., Raju A. and Kashyap Kambhatla P. (2017): Influence of thermophoresis and induced magnetic field on chemically reacting mixed convective flow of Jeffrey fluid between porous parallel plates.- J. Mol. Liq., vol.232, pp.195-206.

[27] Parekh K. And Upadhyay R.V. (2016): The effect of magnetic field induced aggregates on ultrasound propagation in aqueous magnetic fluid.- Journal of Magnetism and Magnetic Materials, vol.431, pp.74-78. http://dx.doi.org/10.1016/j. jmmm.2016.08.024i.

[28] Sinha A. and Misra J.C. (2014): Effect of induced magnetic field on magnetohydrodynamic stagnation point flow and heat transfer on a stretching sheet.- ASME J. Heat Transfer, vol.136, Paper No:HT-11-1549, p.11. https://doi.org/10.1115/1.4024666 
[29] Saleem N., Hayat T. and Alsaedi A. (2012): Effects of induced magnetic field and slip condition on peristaltic transport with heat and mass transfer in a non-uniform channel.- Int. J. Phys. Sci., vol.7, No.2, pp.191-204.

[30] Ibrahim W. (2016): The effect of induced magnetic field and convective boundary condition on MHD stagnation point flow and heat transfer of upper-convected Maxwell fluid in the presence of nanoparticle past a stretching sheet.- Propulsion and Power Research, vol.5, pp.164-175.

[31] Bashtovoi V., Motsar A. and Reks A. (2017): Energy dissipation in a finite volume of magnetic fluid.- J. Magn. Magn. Mater., vol.431, pp.245-248.

[32] Ahmed S., Zueco J. and López-González LM. (2017): Effects of chemical reaction, heat and mass transfer and viscous dissipation over a MHD flow in a vertical porous wall using perturbation method.- Int. J. Heat Mass Transfer, vol.104, pp.409-418.

[33] Gireesha B.J., Mahanthesh B., Shivakumara I.S. and Eshwarappa K.M. (2016): Melting heat transfer in boundary layer stagnation-point flow of nanofluid toward a stretching sheet with induced magnetic field.- Eng. Sci. Technol., an International Journal, vol.19, pp.313-321.

[34] Akrama S. and Nadeem S. (2013): Influence of induced magnetic field and heat transfer on the peristaltic motion of a Jeffrey fluid in an asymmetric channel: Closed form solutions.- J. Magn. Magn. Mater., vol.328, pp.11-20.

[35] Stokes V.K. (1966): Couple Stresses in fluid.- Phys. Fluids, vol.9, pp.1709-1715.

[36] Srinivasacharya D. and Kaladhar K. (2014): Mixed convection flow of chemically reacting couple stress fluid in a vertical channel with Soret and Dufour effects.- Int. J. Comput. Methods Eng. Sci. Mech., vol.15, pp.413-421.

[37] Srinivas J., Adesanya S.O., Ogunseye H.A. and Lebelo R.S. (2018): Couple stress fluid flow with variable properties: A second law analysis.- Math. Meth. Appl. Sci., pp.1-14. DOI: 10.1002/mma.5325

[38] Srinivas J., Adesanya S.O., Falade J.A. and Gajjela N. (2017): Entropy generation analysis for a radiative micropolar fluid flow through a vertical channel saturated with non-Darcian porous medium.- Int. J. Appl. Comput. Math., vol.4, p.3759.

[39] Mahabaleshwar U.S., Sarris I.E., Hill A.A., Lorenzini G. and Ioan Pop. (2017): An MHD couple stress fluid due to a perforated sheet undergoing linear stretching with heat transfer.- Int. J. Heat Mass Transfer, vol.105, pp.157-167.

[40 ]Kaladhar K., Motsa S.S. and Srinivasacharya D. (2016): Mixed convection flow of couple stress fluid in a vertical channel with radiation and Soret effects.- J. Appl. Fluid Mech., vol.9, pp.43-50.

[41] Nasir Ali., Sami Ullah Khan., Muhammad Sajid. and Zaheer Abbas. (2016): MHD flow and heat transfer of couple stress fluid over an oscillatory stretching sheet with heat source/sink in porous medium.- AEJ, vol.55, pp.915-924.

[42] Najeeb Alam Khan, Hassam Khan and Syed Anwar Ali (2016): Exact solutions for MHD flow of couple stress fluid with heat transfer.- J. Egypt. Math. Soc., vol.24, pp.125-129.

[43] Hayat T., Iqbal Z., Qasim M. and Aldossary O.M. (2012): Heat transfer in a couple stress fluid over a continuous moving surface with internal heat generation and convective boundary conditions.- Z. Naturforsch, vol.67, No.5, pp.217-224.

[44] Srinivas J. and Ramana Murthy J.V. (2016): Thermal analysis of a flow of immiscible couple stress fluids in a channel.- J. Appl. Mech. Tech. Phys., vol.57, pp.997-1005.

[45] Adesanya S.O., Falade, J.A. and Rach R. (2015): Effect of couple stresses on hydromagnetic Eyring-Powell fluid flow through a porous channel.- Theor. Appl. Mech., vol.42, No.2, pp.135-150.

[46] Nabil T.M., EL-Dabe., Salwa M.G. and EL-Mohandis. (1995): Effect of couple stresses on pulsatile hydromagnetic Poiseuille flow.- Fluid Dyn. Res., vol.15, pp.313-324.

[47] Srinivas J., Ramana Murthy J.V. and Chamkha A.J. (2016): Analysis of entropy generation in an inclined channel flow containing two immiscible micropolar fluids using HAM.- Int. J. Numer. Methods Heat Fluid Flow, vol.26, pp.1027-1049.

[48] Hayat T., Muhammad T. and Alsaedi A. (2017): On three-dimensional flow of couple stress fluid with CattaneoChristov heat flux.- Chin. J. Phys., vol.55, No.3, pp.930-938.

[49] Kaladhar K. (2015): Natural convection flow of couple stress fluid in a vertical channel with Hall and Joule heating effects.- Procedia Eng., vol.127, pp.1071-1078.

[50] Akhtar S. and Shah N.A. (2016): Exact solutions for some unsteady flows of a couple-stress fluid between parallel plates.- Ain Shams Eng. J., vol.9, No.4, pp.985-992. http://dx.doi.org/10.1016/j.asej.2016.05.008 
[51] Srinivas J. and Anwar Bég, O. (2018): Homotopy study of entropy generation in magnetized micropolar flow in a vertical parallel plate channel with buoyancy effect.- Heat Transfer Res., vol.49, pp.529-553.

[52] Sheikholeslami M., Ganji D.D. and Ashorynejad H.R. (2013): Investigation of squeezing unsteady nanofluid flow using ADM.- Powder Technol., vol.239, pp.259-265.

[53] Adomian G. and Rach R. (1993): Inversion of nonlinear stochastic operators.- J. Math. Anal. Appl., vol.91, pp.39-46.

[54] Adomian G. and Rach R. (1996): Modified Adomian polynomials.- Math. Comput. Model., vol.24, No.11, pp.39-46.

[55] Rach R. (2012): A bibliography of the theory and applications of the Adomian decomposition method, 1961-2011.Kybernetes, vol.41, pp.1087-1148.

[56] Sheikholeslami M., Ganji D.D., Ashorynejad H.R. and Rokni H.B. (2012): Analytical investigation of Jeffery-Hamel flow with high magnetic field and nano-particle by Adomian decomposition method.- Appl. Math. Mech.-Engl., vol.33, pp.1553-1564.

Received: September 14, 2020

Revised: February 9, 2021 